\title{
Neural Representation of Odor-Guided Behavior in the Rat Olfactory Thalamus
}

\author{
Emmanuelle Courtiol and Donald A. Wilson \\ Emotional Brain Institute, Nathan Kline Institute for Psychiatric Research, Orangeburg, New York 10962, and Department of Child and Adolescent \\ Psychiatry, New York University Langone Medical Center, New York, New York 10016
}

The mediodorsal thalamus (MDT) is a higher-order corticocortical thalamic nucleus involved in cognition and memory. However, anatomically, the MDT is also the primary site of olfactory representation in the thalamus, receiving strong inputs from olfactory cortex and having reciprocal connections with orbitofrontal cortex (OFC). Nonetheless, its role in olfaction remains unclear. Here, we recorded single units in the MDT, as well as local field potentials in the MDT, piriform cortex (PCX), and OFC in rats performing a two-alternative odor discrimination task. We show that subsets of MDT units display odorant selectivity during sampling, as well as encoding of spatio-motor aspects of the task. Furthermore, the olfactory trans-thalamic network rapidly switches functional connectivity between MDT and cortical areas depending on current task demands, with, for example, MDT-PCX coupling enhanced during odor sampling and MDT-OFC coupling enhanced during the decision/goal approach compared with baseline and presampling. These results demonstrate MDT representation of diverse sensorimotor components of an olfactory task.

Key words: mediodorsal thalamus; olfaction; olfactory cortico-thalamo-cortical pathway; orbitofrontal cortex; piriform cortex

\section{Significance Statement}

The mediodorsal thalamus (MDT) is the major olfactory thalamic nucleus and links the olfactory archicortex with the prefrontal neocortex. The MDT is well known to be involved in higher-order cognitive and memory functions, but its role in olfaction is poorly understood. Here, using single-unit and local field potential analyses, we explored MDT function during an odor-guided decision task in rats. We describe MDT odor and multisensory coding and demonstrate behavior-dependent functional connectivity within the MDT/sensory cortex/prefrontal cortex network. Our results suggest a rich representation of olfactory and other information within MDT required to perform this odor-guided task. Our work opens a new model system for understanding MDT function and exploring the important role of MDT in cortical-cortical communication.

\section{Introduction}

The mediodorsal thalamus (MDT) is at a unique sensory crossroad linking one of the most primitive sensory systems, the olfactory system, to one of the more recently evolved associative cortices, the orbitofrontal cortex (OFC). The medial and central subnuclei of the MDT receive direct input from primary olfactory areas [piriform cortex (PCX), amygdala, olfactory tubercle, lat-

\footnotetext{
Received Feb. 17, 2016; revised April 5, 2016; accepted April 10, 2016.

Author contributions: E.C. and D.A.W. designed research; E.C. and D.A.W. performed research; E.C. and D.A.W. contributed unpublished reagents/analytic tools; E.C. and D.A.W. analyzed data; E.C. and D.A.W. wrote the paper.

This work was supported by the National Institute on Deafness and Other Communication Disorders, National Institutes of Health (Grant R03DC014540 to E.C. and Grant R01DC003906 to D.A.W.). We thank Gabrielle Girardeau for advice on the initial development of the microdrive and Kacper Kondrakiewicz for help on the initial analysis of the data.

The authors declare no competing financial interests.

Correspondence should be addressed to Emmanuelle Courtiol, Emotional Brain Institute, Nathan Kline Institute for Psychiatric Research, 140 Old Orangeburg Road, Orangeburg, NY 10962. E-mail: ecourtiol@nki.rfmh.org. DOI:10.1523/JNEUROSCI.0533-16.2016

Copyright $\odot 2016$ the authors $\quad 0270-6474 / 16 / 365946-15 \$ 15.00 / 0$
}

eral entorhinal cortex, and anterior olfactory nucleus], as well as from secondary olfactory areas including the OFC and endopiriform nucleus (Powell et al., 1963; Ferrer, 1969; Inagaki et al., 1983; Price and Slotnick, 1983; Price, 1985; Kuroda and Price, 1991; Kuroda et al., 1992; Bay and Cavdar, 2013; Courtiol and Wilson, 2015). The MDT projects massively to the OFC, forming a PCX-MDT-OFC trans-thalamic pathway in addition to the direct PCX-OFC pathway (Krettek and Price, 1977; Illig, 2005).

The MDT, which is characterized by its reciprocal connections with the prefrontal cortex, is involved in various cognitive functions including working memory, goal-directed behavior, and action-outcome association (Orona and Gabriel, 1983; Oyoshi et al., 1996; Kawagoe et al., 2007; Ostlund and Balleine, 2008; Yu et al., 2012; Han et al., 2013; Parnaudeau et al., 2013). The MDT has been also recently hypothesized to be a key node in cortico-thalamo-cortical networks by dynamically driving and synchronizing information transmission to the cortex according to the behavioral demand (Saalmann, 2014). 
A

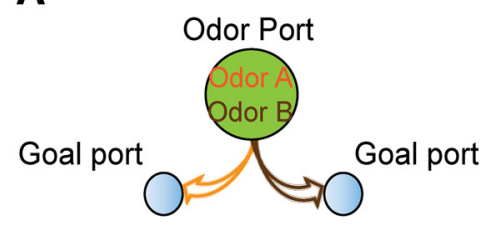

B

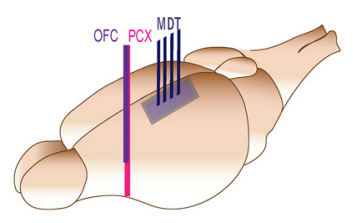

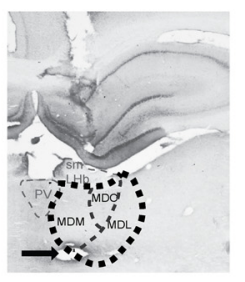

C

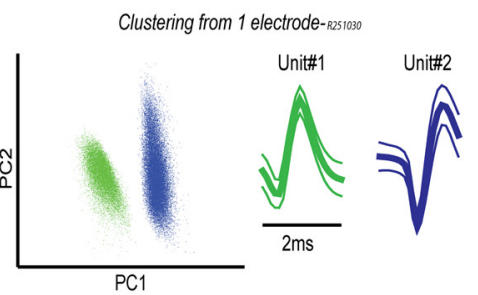

D2

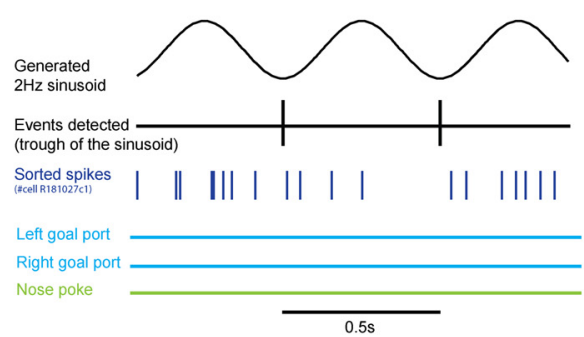

Figure 1. Design of the task and baseline. $\boldsymbol{A}$, Schematic representation of the two-alternative odor discrimination task. $\boldsymbol{B}$, Left, Design of the implantation. Tetrodes were aimed at the MDT and two LFP electrodes were aimed at the PCX and OFC. Right, Example of electrode location in the MDT with the cannulae track as well as the electrolytic lesion site (anteroposterior coordinate $~-2.6$ $\mathrm{mm}$ ). C, Example of spikes-cluster-PCA detection and average spike waveforms on one electrode. D, Baseline period. D1, Baseline period (red) was taken during a quiet awake period $>30 \mathrm{~s}$ (when the animal was awake but not engaged in the task). D2, During the baseline period (enlarged view), a $2 \mathrm{~Hz}$ sinusoid was generated. Each trough of the sinusoid was detected (black). Using the troughs as events, PSTHs of $0.5 \mathrm{~s}$ after the troughs were generated for each unit (with sorted spikes in dark blue) during the baseline period.

Although the relationship of the MDT with the prefrontal cortex and its involvement in cognitive functions are increasingly being established, the role of the MDT in the olfactory network (PCX-MDT-OFC) and, more generally, in olfaction have been woefully unexplored. Indeed, only a very small number of studies have examined the role of MDT in olfaction. MDT units have be shown to respond to olfactory stimulation in various species (Jackson and Benjamin, 1974; Yarita et al., 1980; Imamura et al., 1984; Courtiol and Wilson, 2014). Furthermore, animal lesion studies and more recent human psychophysics and imaging studies have provided evidence of the contribution of the MDT in olfactory perception, discrimination and learning and of the olfactory trans-thalamic pathway in olfactory attention (Eichenbaum et al., 1980; Slotnick and Kaneko, 1981; Plailly et al., 2008; Tham et al., 2009; Zelano et al., 2011).

Understanding the contribution of the MDT to olfaction and in the specific olfactory network is of particular significance as it will not only give insights into the role of the thalamus in olfaction but will also test the function of a specific cortico-thalamocortical pathway. To characterize it, we recorded single units and local field potentials (LFPs) from the MDT as well as LFPs from the PCX and OFC during a two-alternative odor choice discrimination task in freely moving rats. Given the anatomical placement of the MDT in the olfactory pathway, we hypothesized that a subset of MDT units would display odorant selectivity and that a specific recruitment of the PCX-MDT-OFC trans-thalamic pathway would emerge during the odorant sampling period.

Taking advantage of the task design, we also examined (1) the trial initiation period with the underlying hypothesis of anticipatory-related MDT activity and (2) spatial encoding within the MDT based on the hypothesis of the involvement of the MDT in the representation of spatial goals because, in a similar task, OFC neurons have been shown to encode specific spatio-motor variables (Feierstein et al., 2006).

Our results reveal that, not only are a subset of MDT single units odor selective during sampling, but the olfactory transthalamic PCX-MDT-OFC pathway coupling is also dynamically and specifically enhanced during different aspects of the task compared with baseline. Intermingled with this sensory function, we also observed that the MDT displays specific temporal patterns of activity during the presampling period and seems to encode spatio-motor variables. This suggests that MDT neurons may play a crucial role in sensorimotor representation of odorguided behavior.

\section{Materials and Methods}

\section{Animal subjects}

Animal care protocols and all experiments were approved by the Nathan S. Kline Institute Institutional Animal Care and Use Committee and were in accordance with National Institutes of Health guidelines. All efforts were made to minimize pain and discomfort to the animals.

Male Long-Evans rats (250-350 g at the beginning of the experiments) were used as subjects (Harlan Laboratories) and were housed individually in polypropylene cages on a $12 \mathrm{~h}$ light/dark schedule with food ad libitum. Rats were placed under water restriction with access to water provided during the behavioral session and for $30 \mathrm{~min}$ after each session. Rats were weighed daily to ensure that their body weight was not less than $80 \%$ of their body weight at the start of the experiment. Behavioral training and electrophysiological recordings were made during the light phase of the $12 \mathrm{~h}$ light/dark cycle.

\section{Behavioral and chronic electrophysiological experiment Behavioral training}

Odor discrimination was assessed in a two-alternative odor discrimination task (Chapuis and Wilson, 2012; Fig. 1A). Animals received $30 \mathrm{~min}$ training sessions $5 \mathrm{~d}$ per week. The operant chamber was a Plexiglas box $(30 \times 30 \times 40 \mathrm{~cm}$; placed in a Faraday chamber) with a central odor port (located on the central wall) and two goal ports on the left and right walls (Vulintus). Rats started a trial by poking their nose into the central port. The nose poke triggered the delivery of an odor, which terminated on nose withdrawal from the port. Rats were required to hold in the odor port for at least $0.3 \mathrm{~s}$ for the event to be considered a trial eligible for a reward. Water reward $(20 \mu \mathrm{l})$ was delivered, depending on odor identity, upon a correct choice of the left or right goal port within $3 \mathrm{~s}$. The water delivery system was calibrated regularly to ensure that equal amounts of water were delivered at both ports. Animals performed an average of $190 \pm 46$ trials per session ( \pm SD; including hit, errors, and aborted trials, which were defined with a sampling period $<0.3 \mathrm{~s}$ ) in sessions of $30 \mathrm{~min}$. 
The operant chamber was controlled by Spike2 software (Cambridge Electronic Design) and all behavioral epochs were recorded through Spike2.

All animals were first trained on a vanilla versus peppermint (pure extract; McCormick) discrimination until performance $\geq 80 \%$ was attained. Animals required $20 \pm 7 \mathrm{~d}$ (mean $\pm \mathrm{SD}$ ) of training before reaching criterion performance, including initial shaping.

After criterion performance in the vanilla-peppermint discrimination, animals were anesthetized with isoflurane and implanted for electrophysiological recordings. They were allowed at least $10 \mathrm{~d}$ to recover and then restarted the two-alternative odor discrimination task (vanillapeppermint) while their brain activity was recorded. Another odor pair was used after the vanilla-peppermint: ethyl valerate and isoamyl acetate. In some sessions, another slightly different design was also used in which one odor was associated with the left side and five other odors were associated with the right side. Odorants used for this design were pentanol, heptanone, heptanal, as well as the odors used in the two other odor pairs. Odorants were diluted in mineral oil to obtain a concentration for each odorant of $100 \mathrm{ppm}$ except for vanilla and peppermint, which were pure extract (McCormick).

Surgical procedures

Electrodes. Extracellular recordings were obtained by using an adapted movable multitetrode drive developed by Rennaker et al. (2005). The chronic electrode drive consisted of four independently adjustable tetrodes and four cannulae (29 gauge; Ziggy's Tubes and Wires) disposed in the anteroposterior axis. Tetrodes were obtained using $25 \mu \mathrm{m}$ Formwar-insulated Nichrome wires (A-M Systems). Each tetrode was placed in one cannula. Electrode wires were connected to an electrode interface board attached to the multitetrode drive (Omnectics connector EIB-16; Neuralynx). Two stainless steel electrodes (127 $\mu \mathrm{m}$; A-M Systems) were also used to record LFPs in both the PCX and the OFC (Fig. $1 B$, left).

Surgery. Animals were anesthetized and kept unconscious with an isoflurane anesthesia system (E-Z Systems). A surgical level of anesthesia was maintained and monitored throughout the experiment by measuring corneal and paw pinch reflexes. In addition, local anesthetic ( $1 \%$ xylocaine, s.c.) was administered locally around the wound site. Temperature was maintained at $37^{\circ} \mathrm{C}$ throughout the surgery. Animals were placed on a stereotaxic device and the skull was exposed. The bone overlying the left MDT was thinned and removed (coordinates of the window relative to bregma: anteroposterior axis: $\sim-1$ to $-4.5 \mathrm{~mm}$; medianlateral: $\sim 0.2$ to 2 ). Dura was carefully removed. The movable multitetrode drive was chronically implanted in the left hemisphere and aimed at the MDT with coordinates of the more anterior tetrode: $\sim-2$ and the most posterior: $\sim-3.6$; lateral coordinates ranging between $\sim 0.4$ and $1.4 \mathrm{~mm}$ relative to bregma. The tetrodes were placed ventrally right above the MDT ( $\sim 4-5 \mathrm{~mm}$ ventral to the surface of the brain). Once the movable multitetrode drive was implanted, the remainder of the opened window was filled with silicone elastomer (KWIK cast; World Precision Instruments) and the multitetrode drive was cemented to the rat's skull. Two holes were also made over the ipsilateral PCX and OFC (coordinates: anteroposterior: +3.8 ; median-lateral: +2.8 relative to bregma; Fig. $1 B$, left). The LFP electrodes were attached together; the distance between the two tips was $1.5 \mathrm{~mm}$ with one extending in the OFC $(\sim 4.5$ $\mathrm{mm}$ ventral to the surface of the brain) and the other in the PCX $(\sim 6 \mathrm{~mm}$ ventral to the surface of the brain). LFP electrodes were cemented to the rat's skull. Reference and ground electrodes were connected to screws over the right posterior cerebral cortex and over the cerebellum. Two additional bone screws were added over the right frontal cortex to secure the cement. Immediately after the surgery and before recovery, animals were treated with the analgesic buprenorphine $(0.1 \mathrm{mg} / \mathrm{kg}$, s.c. $)$ and again the following day. The antibiotic enrofloxacin $(5 \mathrm{mg} / \mathrm{kg}$, s.c.) was also delivered after the surgery. For at least $3 \mathrm{~d}$ after the surgery, rats were complemented with the antibiotics Baytril $(0.5 \mathrm{mg} /$ tablet; bacon flavor; Bio Serv). The rats were allowed to recover for at least $10 \mathrm{~d}$.

Electrophysiological recordings

Neural data were collected and preamplified with 16-channel head stage (model 3600; A-M Systems). Data were then transmitted to a 16-channel extracellular amplifier (A-M Systems) through a commutator. Signals were acquired (sampling rate: 10 and $20 \mathrm{kHz}$ ), band-pass filtered ( $300-$ $3000 \mathrm{~Hz}$ for the unit activity and $1-3000 \mathrm{~Hz}$ for the LFPs), amplified (2000 times for the single units and 200 times for the LFPs channels), digitized, and recorded though Spike2 software (Cambridge Electronic Design). Note that we implanted four tetrodes and two LFPs electrodes in the OFC and PCX, but for one of the four tetrodes, not all of the electrodes were recorded.

Neural activity was recorded while the rats were performing the twoalternative odor discrimination task. Each tetrode was lowered daily at the end of each session to a new recording site. The daily advancing distance was between $\sim 100$ to $180 \mu \mathrm{m}$. Each day, different neurons were recorded.

\section{Analysis of electrophysiological data}

Neural and behavioral data were analyzed offline using Spike2, scripts in MATLAB (The MathWorks), and Excel.

Spike sorting. Isolation of single units was done using a combination of template matching and clustering based on PCA in Spike2. Depending of the quality of the tetrode, isolation of single units was either on a single electrode (in that case, only one of the four electrodes composing a tetrode was analyzed; Fig. 1C) or two or four electrodes of one tetrode. Single units were required to have $<0.5 \%$ of the spikes occurring within a refractory period of $1 \mathrm{~ms}$ (as described in Feierstein et al., 2006). Spike trains of units recorded in the operant chamber were analyzed relative to the different behavioral epochs.

Epoch definitions. A task window was generated based on behavioral measurements during active rapid trial generation. Over the different session files analyzed with units detected (94 sessions), the mean sampling duration was as follows: $0.57 \pm 0.09 \mathrm{~s}$ (average of the mean value per rat per session $\pm S D$ ); the mean duration between the end of the sampling period and the goal port onset was $0.88 \pm 0.13 \mathrm{~s}$ (mean \pm SD) and the mean duration between the end of the goal port and the beginning of a new trial was $1.205 \pm 0.21 \mathrm{~s}$ (mean $\pm \mathrm{SD}$; the mean of the minimal values per rat-session for this period was $0.55 \mathrm{~s} \pm 0.13$; those values were analyzed from trials with a maximum duration of no more than $3 \mathrm{~s}$ between the goal port exit and nose poke onset). Periods of interest were defined as follows (Fig. $2 A$ ): the presampling period was defined as $-0.5 \mathrm{~s}$ to nose poke onset, the sampling period was defined as nose poke onset to $0.55 \mathrm{~s}$ after nose poke onset, and the postsampling period was defined either as the period between $0.55-1.5 \mathrm{~s}$ after nose poke onset or as the $0.5 \mathrm{~s}$ preceding the goal port onset depending on the analysis. The task window was thus defined as a window of $2 \mathrm{~s}$ starting $0.5 \mathrm{~s}$ before nose poke onset and ending $1.5 \mathrm{~s}$ after nose poke onset. This window allowed us to capture, not only the trial initiation and the sampling period, but also the decision period and goal port entry.

Single-unit event-related peristimulus time histogram (PSTH) analysis. To compare neural activity with the different periods of interest and events, single-unit spiking activities were aligned with stimuli of interest in the task and PSTHs (50 ms bins) were generated on all trials (hit, errors, and aborted trials) unless noted otherwise.

Analysis of task-modulated units. We calculated whether the single units were significantly modulated during the task window $(-0.5 \mathrm{~s}$ to $1.5 \mathrm{~s}$ after nose poke onset). Unit activities were assessed over the $2 \mathrm{~s}$ task window with a sliding window of $200 \mathrm{~ms}$ over bins of $50 \mathrm{~ms}$ and with 100 ms step using the Friedman test. To be included as task modulated, MDT units had to present a significant modulation of activity for at least one of the odors presented. Only units presenting a significant $p$-value $(p<$ 0.05 ) of the Friedman test were considered as task modulated and were used for further analysis.

Activity compared with baseline. A majority of studies using the twoalternative task have used the presampling period as a baseline. In our specific case, the MDT displayed strong variations of activity during the presampling period. Therefore, for the analyses here, the baseline period was taken during a quiet awake period $>30 \mathrm{~s}$ (either one period $>30 \mathrm{~s}$ or two or three combined to have at least $30 \mathrm{~s}$; Figure 1D1; Cohen et al., $2015)$ in the operant box. To be able to compare the baseline activity with our different epochs and include to some extent the variability of activity during the course of the baseline, we randomly generated a $2 \mathrm{~Hz}$ sinusoid. 
A
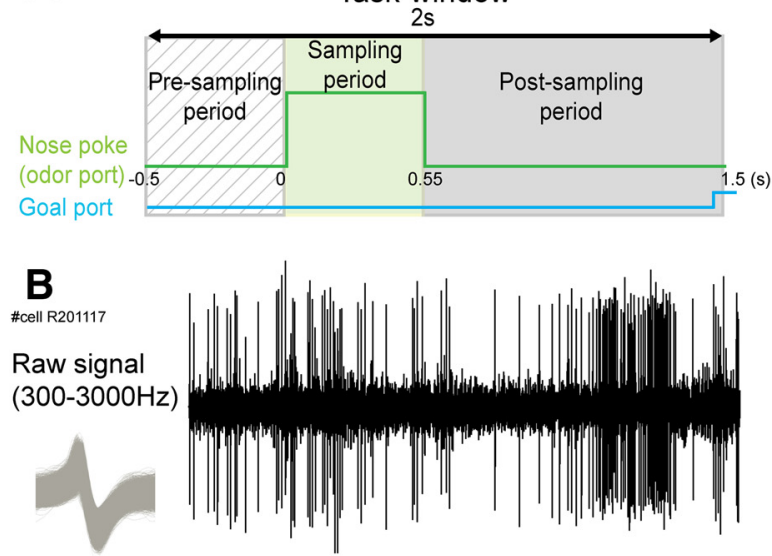

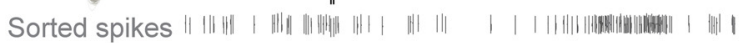
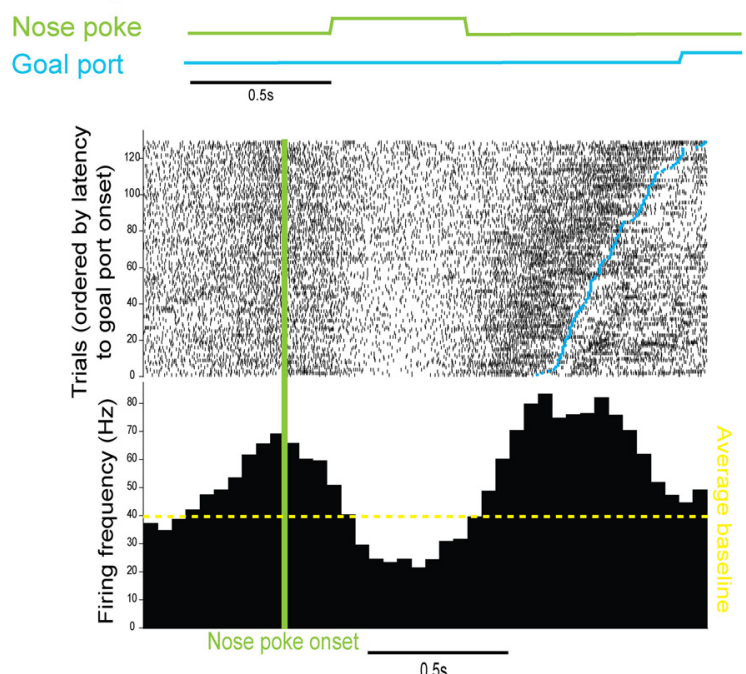

C Units recorded simultaneously during one session (R251112) \#cell 2

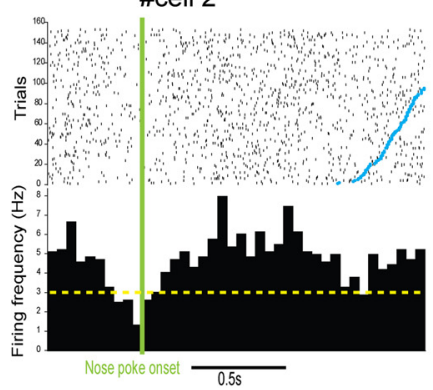

\#cell 3

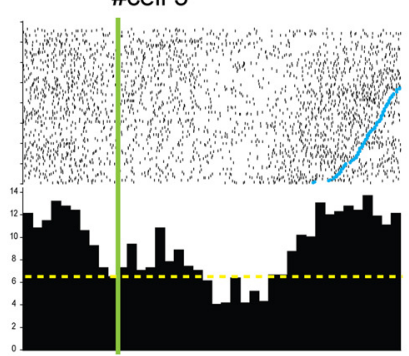

\#cell 4

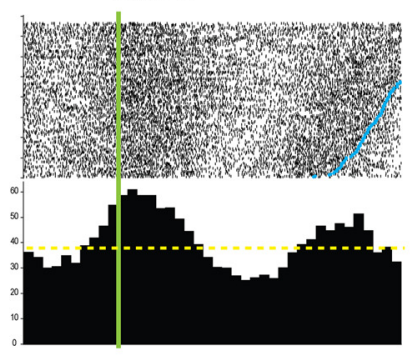

D Units recorded simultaneously during one session(R251112)

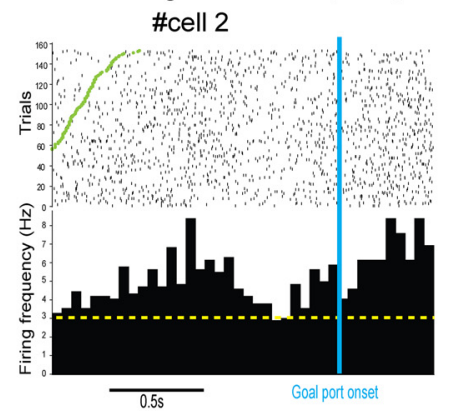

\#cell 3

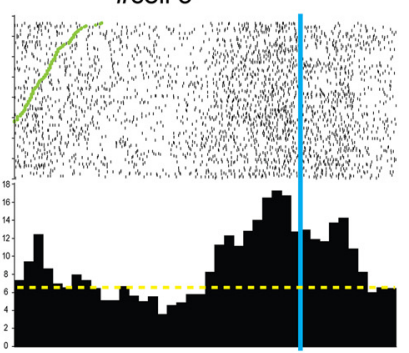

\#cell 4

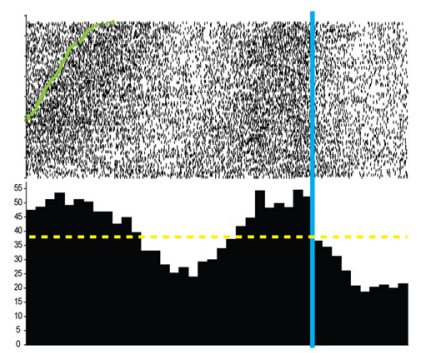

Figure 2. Modulation of MDT unit activity during the task window. $A$, Olfactory discrimination task window of interest. The task period used was a window of $2 \mathrm{~s}$. This window was divided into three periods: presampling (diagonal dashed line), sampling (green), and postsampling (gray). B, Example of a task-modulated unit. Top, from top to bottom, Waveform activity of the taskmodulated unit (raw signal, $300-3000 \mathrm{~Hz}$ ) over one trial with the associated average waveform shape of sorted spikes (in gray). Sampling period is represented in green and goal port period in blue. Bottom, Raster plots and PSTH of the task-modulated unit represented in the top panel during the task window. Data for raster plot and PSTH were obtained by extraction of single-unit activity from the raw recording. Raster plot and PSTH are triggered by the nose poke onset (green) and trials are ordered by latency to goal port onset (blue dots). The average baseline (see Materials and Methods and Fig. 1D1,D2) is represented here and in all subsequent figures with a dashed yellow line. $\boldsymbol{C}, \mathbf{D}$, Examples of raster plots and PSTHs of three units recorded simultaneously during one session. Data are triggered by the nose poke onset in $\boldsymbol{C}$ (green) and the goal port onset in $\boldsymbol{D}$ (blue), with trials ordered by latency to goal port onset (blue dots) and by nose poke onset (green dots) in $\boldsymbol{C}$ and $\boldsymbol{D}$, respectively.

Each trough of the sinusoid was detected to create triggers (Fig. 1D2). This allowed us to have PSTHs of $0.5 \mathrm{~s}$ with $50 \mathrm{~ms}$ bins. Each period, presampling ( $0.5 \mathrm{~s}$ to nose poke onset), global sampling (all odors grouped together, period from nose poke onset to $0.55 \mathrm{~s}$ after nose poke onset), and postsampling period ( $0.5 \mathrm{~s}$ to goal port onset, including all trials except the aborted trials), was compared with baseline activity using the Wilcoxon rank-sum test $(p<0.05)$. When comparing each odor period with baseline activity, the Wilcoxon rank-sum test with Sidak's correction for multiple comparisons was used. Units with a significant increase in activity relative to baseline were deemed excitatory and units with a significant decrease in activity relative to baseline were deemed suppressive.

Stimulus-dependent activity. Significant difference of activity during the sampling period between two odors was assessed using the Wilcoxon signed-rank test $(p<0.05)$. To compare the sampling activity between the five odors associated with the same goal port, a Friedman test was applied $(p<0.05)$. In addition, to examine single-unit population responses to different odors, correlations between the activity of all cells tested in the five-odor paradigm were performed in $50 \mathrm{~ms}$ increments across the trial, starting $500 \mathrm{~ms}$ pretrial initiation and ending $1.5 \mathrm{~s}$ posttrial initiation. All pairwise correlations (across all five test odors, i.e., 10 possible pairs) of activity in these $50 \mathrm{~ms}$ bins were determined, converted to $z$-scores (Fisher conversion function), and tested for significant changes over time using a repeated-measures ANOVA followed by Fisher's post hoc tests.

Significant differences between hit and error trials during the postsampling period defined as $0.55-1.5 \mathrm{~s}$ after nose poke onset (considering only sessions with $\leq 75 \%$ performance and with at least 14 trials for each odor-hit/error conditions); between moving to the right or the left goal port during the $0.5 \mathrm{~s}$ preceding goal port onset (including all trials except the aborted trials); and between coming from the right or from the left toward the central port during the $0.5 \mathrm{~s}$ preceding nose poke onset (including only trials for which the duration between the end of the goal port and the nose poke onset was $<2 \mathrm{~s}$ ) were assessed using the Wilcoxon signed-rank test $(p<0.05)$.

LFP analysis. LFPs were recorded in the PCX, OFC, and MDT (one electrode from one of the tetrodes was recorded full-band at -1 to $3000 \mathrm{~Hz}$ ).

Spike-LFP phase-locking analysis. LFPs were filtered into three different frequency bands: theta $(1.5-12 \mathrm{~Hz})$, beta $(15-35 \mathrm{~Hz})$, and gamma $(40-90 \mathrm{~Hz})$. Cycles (negative troughs) were then detected using a threshold of 1 SD (measured during a quiet awake baseline period of $>30 \mathrm{~s}$ ) of the filtered signals in the 3 different brains areas (MDT, PCX, and OFC). 
Phase locking was assessed for each oscillatory frequency band during 4 different epochs of $0.5 \mathrm{~s}$ : baseline, presampling $(-0.5 \mathrm{~s}$ to nose poke onset), sampling ( $0.5 \mathrm{~s}$ after nose poke onset; we choose to reduce the sampling period to $0.5 \mathrm{~s}$ after nose poke onset to be able to compare it with the baseline, presampling, and pregoal port onset periods), and pregoal port periods ( $-0.5 \mathrm{~s}$ to goal port onset; number of bins: 50 ). Units that fired $<20$ spikes in each condition were not analyzed. MATLAB software was used to determine significance of individual unit activity phase relationship with theta, beta, and gamma cycle using Rayleigh statistics for circular uniformity (MATLAB circular statistics package). Comparisons of the proportion of phase-locked units between the different epochs were performed using $\chi^{2}(p<0.05)$. In addition, the mean phase angle and the mean resultant vector length was calculated for each unit in each condition using MATLAB circular toolbox (scripts: circ_mean and circ_r). Population vectors representing the average of the mean phase angle and resultant vector length of MDT units in each condition were then calculated using MATLAB circular statistics toolbox.

Power spectra. Power spectra (FFT, fast Fourier transform; Hanning window, resolution: $2.44 \mathrm{~Hz}$ ) were calculated during 4 different epochs of $0.5 \mathrm{~s}$ : baseline, presampling, sampling, and pregoal port periods as for the phase-locking analysis. FFT values were averaged by frequency band (due to the resolution of the FFT over the $0.5 \mathrm{~s}$, the frequency bands were defined as $2.44-12.2 \mathrm{~Hz}$ for theta, $14.6-36.6 \mathrm{~Hz}$ for beta, and 39.1-90.3 $\mathrm{Hz}$ for gamma). The values per frequency band were then averaged across animals. A repeated-measures ANOVA was used to compare the FFT values in each frequency band across the four different periods followed by Fisher's post hoc tests.

\section{Histology}

After recordings, animals were overdosed with urethane anesthetic. DC current was applied to the electrode wires $(50 \mu \mathrm{A}, 5 \mathrm{~s})$ to mark recording sites. Animals were then transcardially perfused with $0.9 \%$ saline and $10 \%$ formalin. Brains were removed and stored in a $30 \%$ sucrose $/ 10 \%$ formalin solution before sectioning. Coronal brain sections $(40 \mu \mathrm{m}$ thick) were performed and stained with cresyl violet for determination of electrode positions and electrolytic lesions under a light microscope (Fig. $1 B$, right).

\section{Results}

Activity in the MDT during active performance of the twoalternative odor discrimination task

Eight rats were trained to perform a two-alternative odor choice discrimination task (Fig. 1A). After initial training, rats were implanted with a chronic multitetrode drive consisting of four independently adjustable tetrodes over the MDT. LFP electrodes were also implanted in the PCX and OFC (Fig. 1B) and 207 MDT units were recorded in these eight rats. During recordings, rats performed an average of 190 trials $\pm 46( \pm S D)$ over 94 sessions analyzed. Seven odors were used across all sessions, with a total of 674 unit-odor pairs analyzed. A trial is defined as follows: a rat initiates a trial by poking his nose in a central port (odor port). This triggers the delivery of an odor. After withdrawing his nose from the central port, the rat has to respond by moving either to the right or left goal port depending on odor identity. Water reward is delivered if the rat makes the correct choice. Over the different sessions in which units were detected, the mean odor sampling duration was as follows: $0.57 \pm 0.09 \mathrm{~s}$ (average of the mean value per rat-session $\pm S D$ ), the mean duration between the end of the odor sampling period and the goal port entry was $0.88 \pm 0.13 \mathrm{~s}( \pm \mathrm{SD})$, and the mean duration between exiting the goal port and initiating a new trial was $1.205 \pm 0.21 \mathrm{~s}( \pm \mathrm{SD}$; the mean of the minimal values per rat-session for this period was $0.55 \mathrm{~s} \pm 0.13)$. Our duration of interest for each trial was thus a $2 \mathrm{~s}$ window (Fig. $2 A$ ) with 3 epochs: a presampling period defined as the $0.5 \mathrm{~s}$ period preceding the nose poke onset, a sampling period defined as the period from nose poke onset to $0.55 \mathrm{~s}$ after the nose poke onset, and a postsampling period defined either as the period between $0.55 \mathrm{~s}$ and $1.5 \mathrm{~s}$ after the nose poke onset or as the 0.5 s period preceding the goal port onset.

We first wanted to decipher whether MDT units were significantly modulated at any point during the entire $2 \mathrm{~s}$ window of the olfactory discrimination task using a sliding window analysis of single-unit firing rate (Fig. $2 A$ ). We observed that $75 \%$ of MDT units presented a significant modulation of activity over the $2 \mathrm{~s}$ task window for at least one of the odors presented during the task (155/207, Friedman test, sliding window of $200 \mathrm{~ms} ; 50 \mathrm{~ms}$ bins; $100 \mathrm{~ms}$ step, $p<0.05$ ). Examples of units significantly modulated over the task window are presented in Figure 2. Importantly, as represented in Figure 2, different modulation patterns can be observed during the task window. Those modulations can appear during the presampling, sampling, and/or the postsampling periods. Therefore, the activity of MDT units can be represented either aligned to the nose poke onset (Fig. $2 B, C$ ) or to the goal port onset (Fig. $2 D)$. Importantly, similar patterns of single-unit activity can be found in different animals (Fig. $2 B, C$, bottom) and different patterns of activity can be observed from simultaneously recorded single units (Fig. $2 C$ ).

Further analyses were performed only on these taskmodulated units $(n=155)$. Our first aim was to characterize the odorant selectivity of the MDT and the relationships within the PCX-MDT-OFC pathway during the sampling period in a twoalternative odor discrimination task.

\section{Odorant representation in the MDT}

\section{Odorant selectivity}

To better understand the sensory specificity and odor representation in the MDT during the two-alternative odor discrimination task, we characterized MDT single-unit activity during the sampling period and the dynamic changes in spike-LFP coupling between MDT single units and LFPs in the MDT, PCX, and OFC over the course of the task window.

We first compared the global sampling activity (all odors combined) of each cell relative to baseline. Given that thalamocortical activity has been shown to be sensitive to many taskdependent stimuli and actions (Schoenbaum and Eichenbaum, 1995; Feierstein et al., 2006; Mair et al., 2015) and because one goal of the present study was to identify clearly such taskdependent activity in the MDT, we chose as our baseline a period when the animal was in the task context, but not engaged in the task. Baseline single-unit firing rate was calculated over a quiet awake period $>30 \mathrm{~s}$ in the operant box (see Materials and Methods and Fig. 1D1,D2). We chose this specific period as a baseline rather than the presampling period because we observed strong variations of MDT activity during the presampling period and because we wanted to have a common baseline for all our epochs.

Using the quiet awake period as a baseline, we observed that $59 \%$ of MDT single units present a significant difference of firing rate between sampling period and baseline (92/155; Wilcoxon rank-sum test, $p<0.05$ ). Of those units, excitation (compared with the baseline) represents $56.5 \%$ (Fig. $3 A, B$ ). However, as illustrated in Figures $2 B$ and $3 B$ (right), the firing rate of some units starts to increase before the sampling period onset and may thus not represent odor-driven activity. To further explore this, we examined the difference between baseline and the sampling period for each individual odor tested in the two-odor task $(n=$ 103 single units). We observed that $21 \%$ of MDT units displayed a significant difference of activity between the sampling period 
A

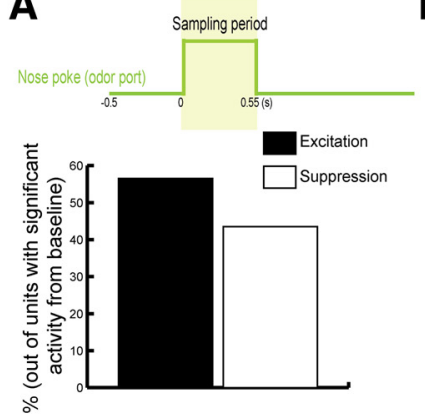

C1
B

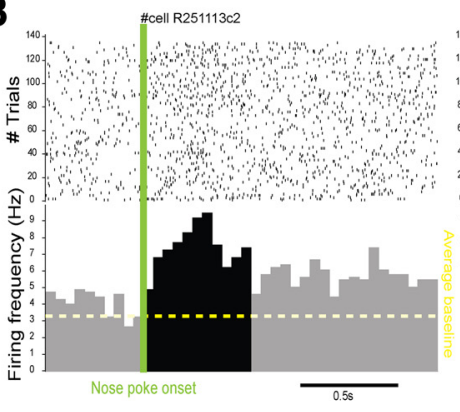

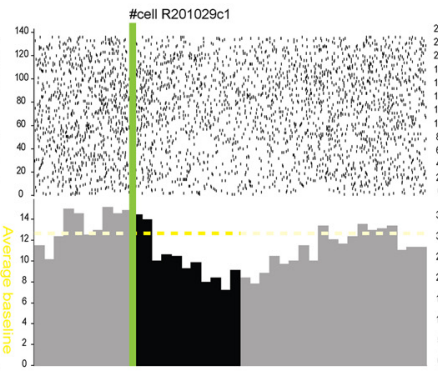

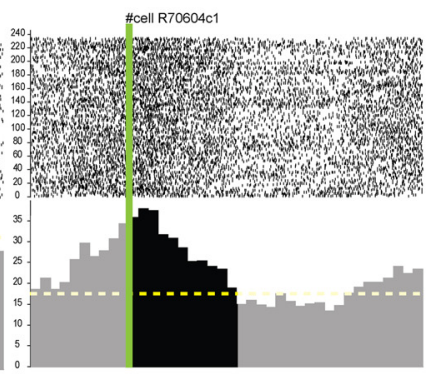

C2

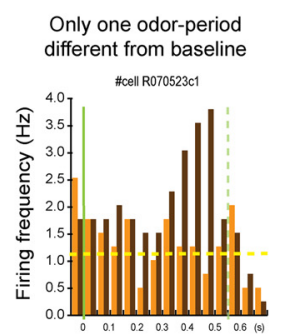

Difference from baseline

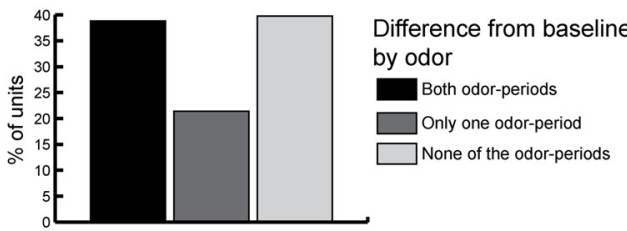

\section{C2}

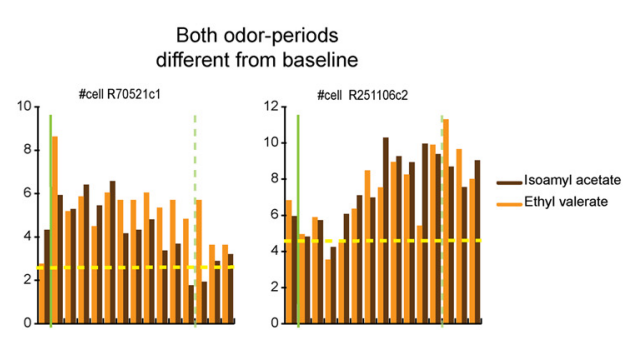

Figure 3. Sampling activity of MDT units compared with baseline. A, Activity during the sampling period (in green, $0.55 \mathrm{~s}$ after nose poke onset) was compared with baseline activity (Wilcoxon rank-sum test, $p<0.05$; Fig. 1D). Histogram of the percentage of units (of the units with a significant difference of activity from baseline $n=92 / 155$ ) with an activity deemed excitatory (black) or suppressive (white). $\boldsymbol{B}$, Examples of raster plots and PSTHs of three units with global sampling activity significantly different from baseline. Raster plots and PSTHs are triggered by the nose poke onset (green). The period of interest (i.e., sampling period) is represented here and in subsequent figures in black in the PSTHs. C, Sampling activity compared with baseline for each odor used. The units used were the ones recorded using the simple two-odor design $(n=103)$. C1, Percentage of units with both odor-sampling period activities different from baseline (black), with only one of the odor-sampling period activities different from baseline (dark gray) and with neither of the odor-sampling period activities different from baseline (light gray, Wilcoxon rank-sum test, Sidak's correction). C2, Example of peristimulus activity triggered by the nose poke onset (green) as a function of the odor presented (isoamyl acetate in brown and ethyl valerate in orange) for three different units. Left to right, Cell R070523c1 presents only one of its odor-sampling period activities significantly different from baseline; cells R70521c1 and R251106c2 display activities during both odor-sampling periods that are significantly different from baseline.

and the baseline for one of the odors but not the other $(22 / 103$; Wilcoxon rank-sum test, Sidak's correction; Fig. 3C1,C2, left), suggesting odor specificity in the response. Of the other single units, $40 \%$ displayed no significant difference of activity between sampling period and baseline for either odor (41/103) and 39\% displayed a significant difference of activity between the sampling period and the baseline for both odors used (40/103; Fig. 3C2, right). In this latter case, it is difficult to disentangle the odorant specificity and the influence of other variables because both odor periods are different from baseline but may or not be different from each other (Fig. 3C2, right). Therefore, in addition to comparing sampling-related activity with baseline for both odors, we also compared the sampling period activity between the two odors used in each pair for each MDT single unit and observed that $15 \%$ of MDT units displayed a significant difference of activity between the two stimuli (15/103, Wilcoxon signed-rank test, $p<0.05$; Fig. $4 A$ ). The fact that $15 \%$ of MDT units recorded during the simple two-odor discrimination task displayed a significant difference of sampling activity between the two odors suggests that MDT can display odorant selectivity. In fact, in a two-alternative odor choice task, each odor is associated with an identical reward so the stimuli are not predictive of a specific valence. However, and as highlighted by Feierstein et al. (2006), each odor is associated with a specific goal port. In this case, the stimuli can be predictive of the goal port location or the choice direction. To disentangle whether, during the sampling period, the MDT units were selective to odorant stimuli, we used a slightly different design. In this design, odor A was also associated with the left side, but, instead of using only one odor associated with the right side, we used five different odors within the same session (Fig. 4B1). In this specific case, the five odors are associ- ated with identical water reward and are associated with the same goal port location. If MDT units encode odor information, then they should discriminate among odors associated with the same goal port. We compared the sampling activity between the odors associated with the same goal port. Of the 52 units recorded in this configuration, $25 \%$ displayed significantly different activity between the odors associated with the same goal port (13/52, Friedman test, $p<0.05$; Fig. 4B1).

In addition, we analyzed the activity of those 52 units as a population. We computed how activity within $50 \mathrm{~ms}$ bins on trials with a given odor correlated with activity in those same cells at that same time point on trials with a different odor. In this dataset, all odors signaled the same reward port. Correlations were determined on activity in $50 \mathrm{~ms}$ bins starting 500 ms before trial initiation (odor onset) and ending $1.5 \mathrm{~s}$ after trial initiation. Correlation time series for each odor pair (10 pairs) were converted to $z$-scores and averaged across all pairs. As illustrated in Figure 4B2, the correlated population activity significantly changed across time $\left(F_{(9,39)}=17.161, p<0.001\right)$. For example, as trial initiation approached, population activity across odors was highly correlated (correlation coefficient: 0.954 ), suggesting the attainment of a similar state of MDT activity across trials before odor onset. In contrast, during the odor sampling period, MDT population activity showed a strong decorrelation between odors, which peaked immediately before the animal chose to exit the odor port (correlation coefficient: 0.791 ) and then progressively returned toward starting levels. Therefore, MDT single-unit populations show a significant decorrelation in activity during sampling of different odors.

Together, these results are a firm demonstration that a subset of MDT units can encode odorant stimulus information selectively. 
A
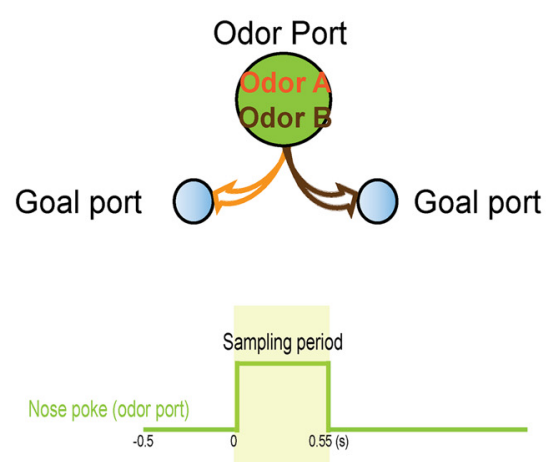
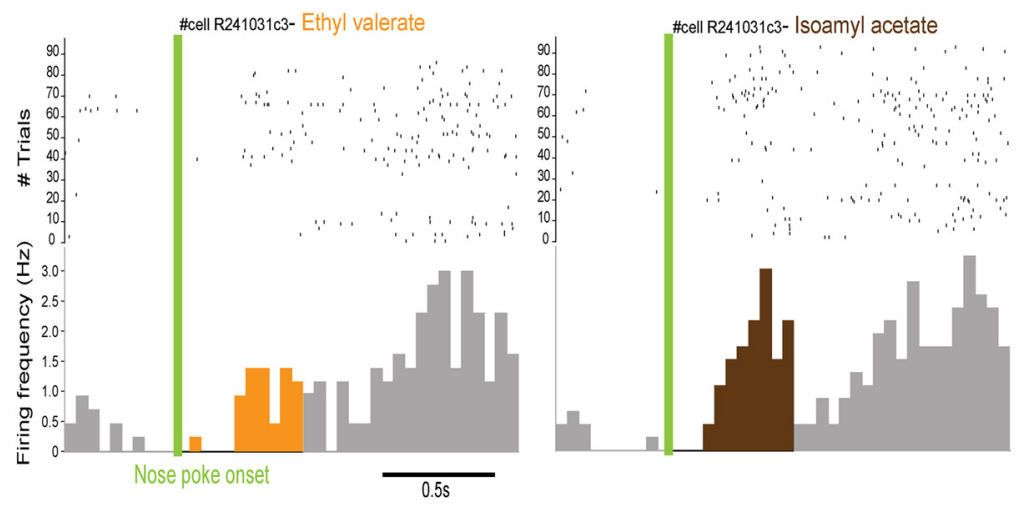

B1
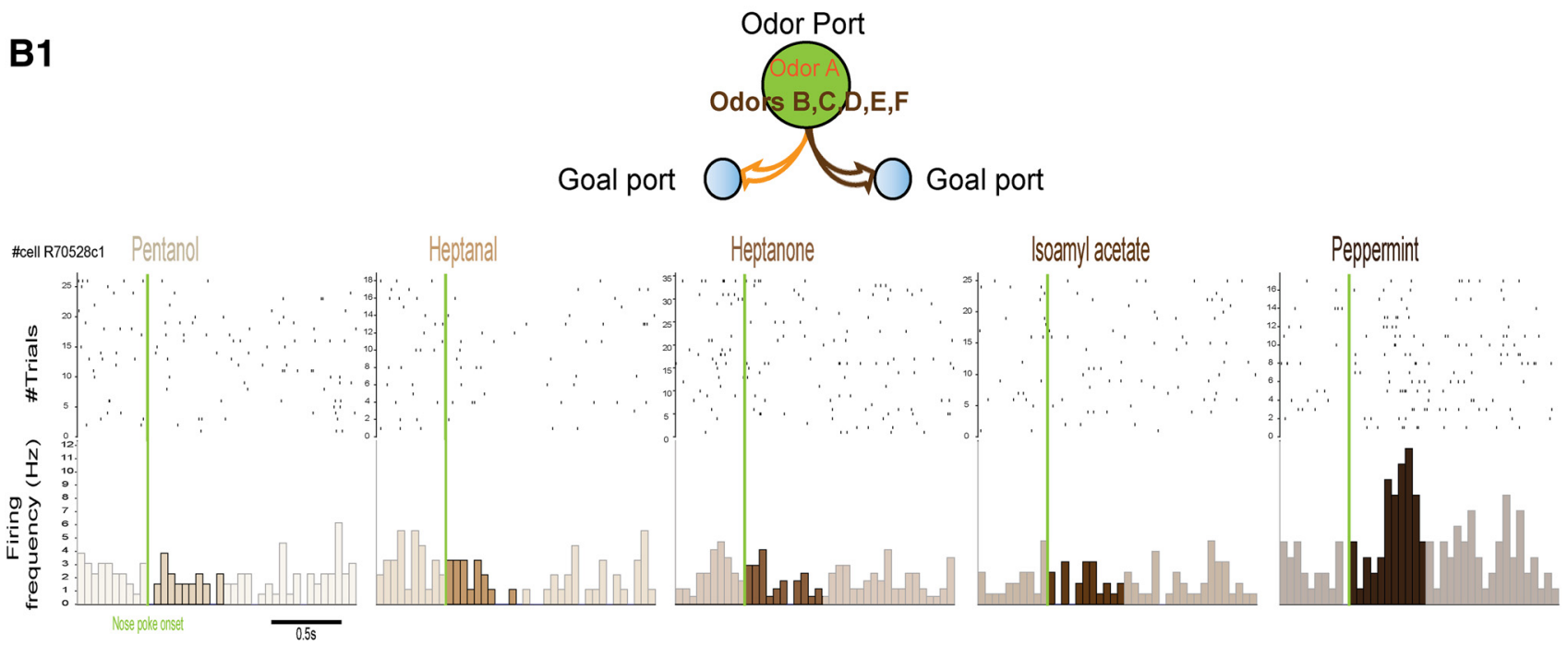

\section{B2}

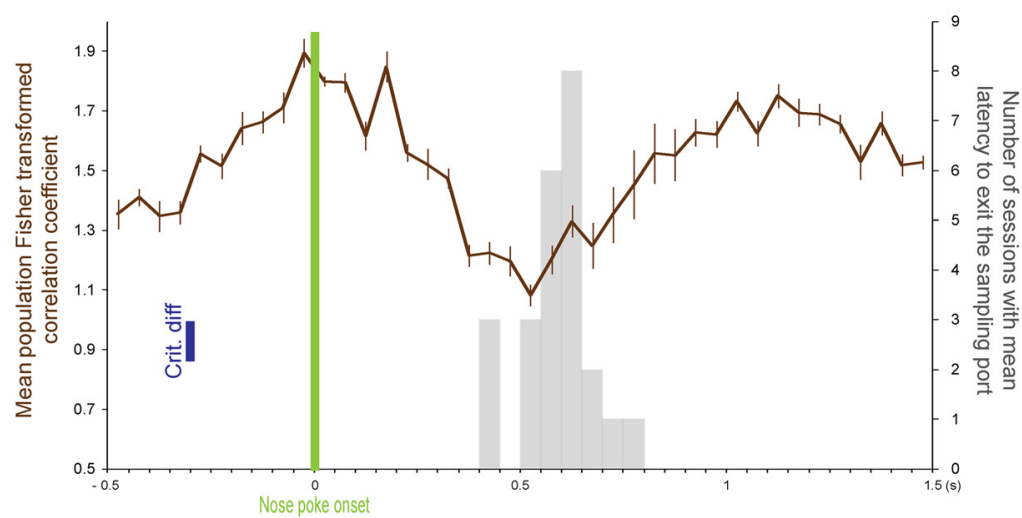

Figure 4. Stimulus selectivity in rat MDT. $A$, Odorant selectivity of MDT units recorded in the simple two-odor discrimination task. Example of one unit displaying a significant difference of sampling activity ( 0.55 s period after nose poke onset) between ethyl valerate and isoamyl acetate (Wilcoxon signed-rank test, $p<0.05)$. Raster plots and PSTHs are triggered by the nose poke onset (green). B, Odorant selectivity of MDT units recorded in a modified two-alternative odor discrimination task. Odor A is associated with the left and odors B-F are associated with the right. B1, Example of one unit displaying a significant difference of sampling activity between the odors associated with the same port. B2, Mean ( \pm SEM) Fisher-transformed correlation coefficients (z-scores) of MDT unit population (52 units) triggered by the nose poke onset (averaged over the 10 different comparisons between the five odors associated with the same port). In blue is represented the critical difference (crit. diff. $=0.133$, Fisher's post hoc test) for point-to-point comparisons. In gray (right) is represented the histogram distribution of the mean latency to terminate odor sampling across animals and sessions from which the 52 units were recorded.

Dynamic relationships among the MDT, PCX, and OFC

The MDT single-unit activity described above occurs within the context of a larger cortical network, the olfactory corticothalamo-neocortical pathway (PCX-MDT-OFC). To explore MDT single-unit activity within this network and to determine how task demands shape regional functional connectivity, we recorded single units as well as LFP in the MDT while simultaneously recording LFPs in both PCX and OFC (Fig. 5A). As a measure of network connectivity, we analyzed the MDT spike phase locking to LFP oscillations recorded in the MDT, PCX, and OFC. 
A

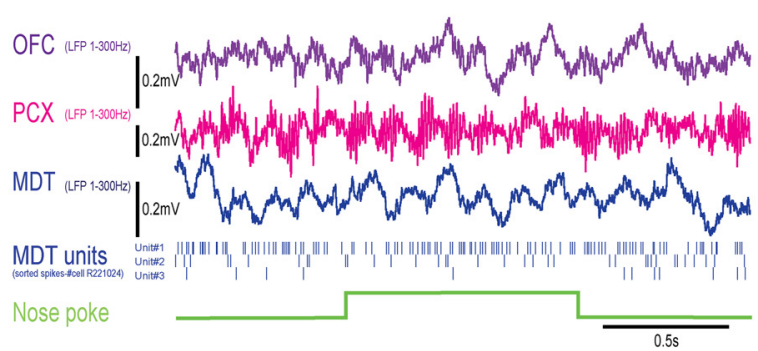

B

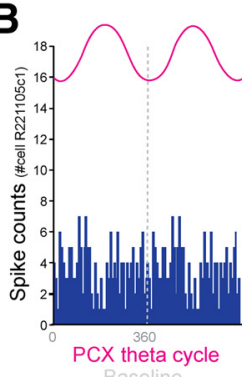

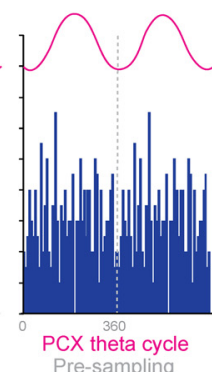

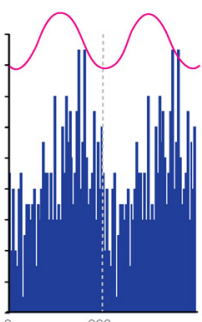

PCX theta cycle Sampling

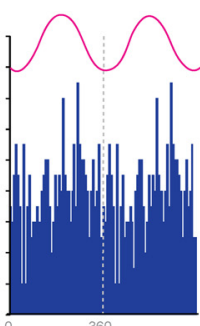

PCX theta cycle Pre-goal port onset

C
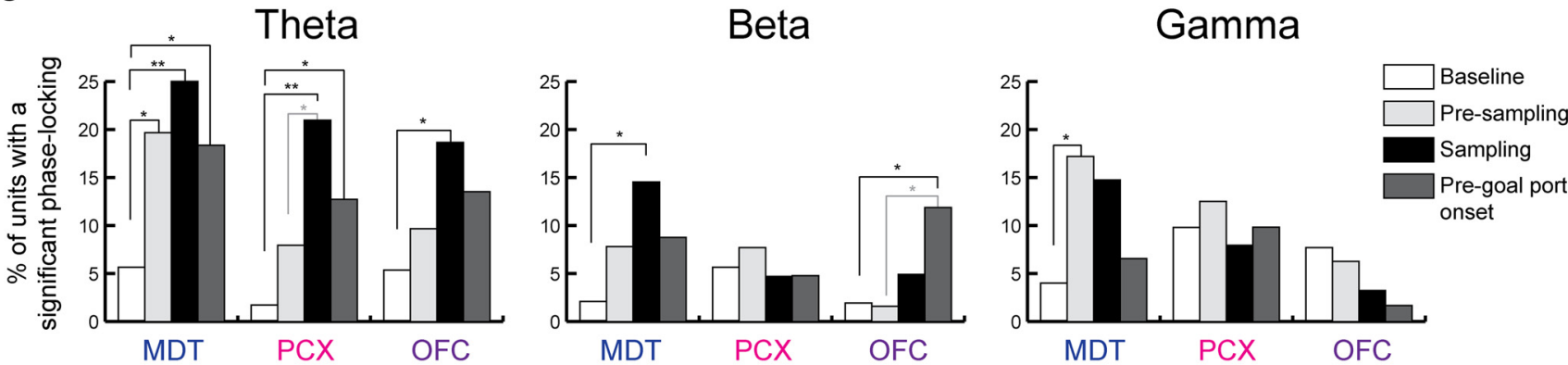

D
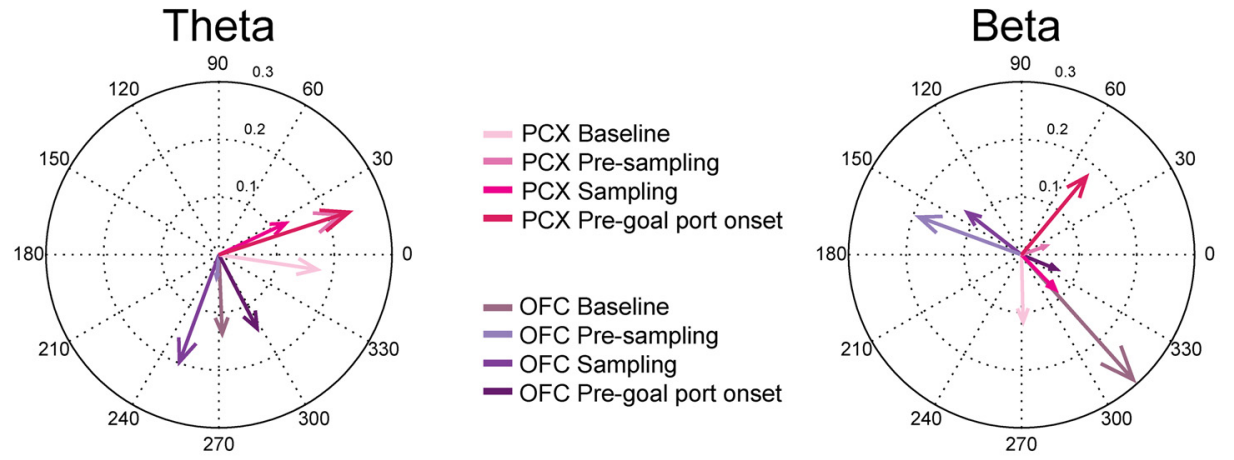

$\mathbf{E}$

$\begin{array}{llll}\text { Nose poke } & & \\ \text { (odor port) } & \text { Pre-sampling } & \text { Sampling } & \text { Pre-goal port } \\ \text { Goal port } & & \end{array}$
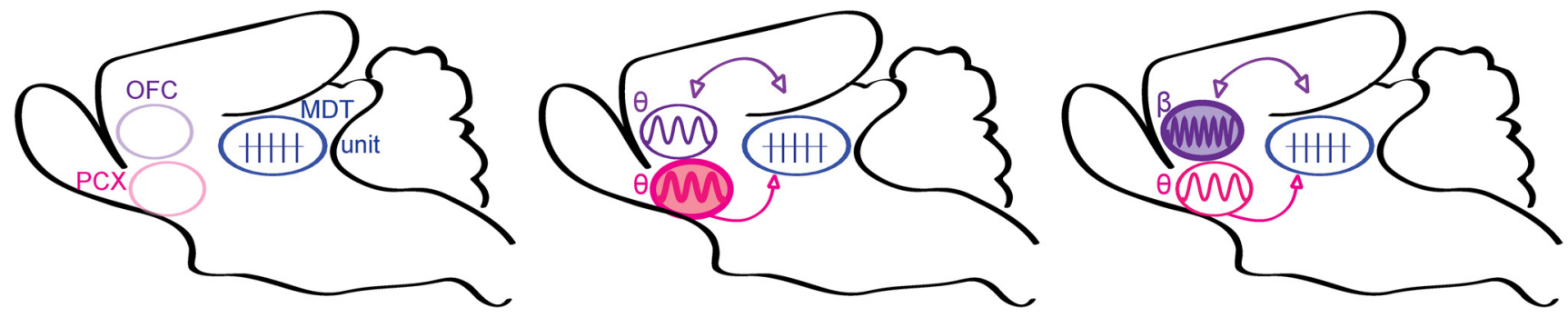

Figure 5. Dynamic changes of the PCX-MDT-OFC trans-thalamic pathway during the olfactory task window. $A$, Examples of LFP and MDT unit recordings during a trial (nose poke in green). Top to bottom, LFPs (1-300 Hz) recorded in OFC (violet), PCX (pink), and MDT (blue) and spikes detected from three simultaneously recorded MDT units. $\boldsymbol{B}$, Example of MDT unit activity distribution relative to the phase of theta oscillations recorded in PCX during baseline, presampling, sampling, and pregoal port onset periods (from left to right). Two cycles are represented and the dashed gray line represents the separation between the two theta cycles. C, Percentage of MDT units with a significant phase locking (see Materials and Methods) to LFP theta, beta, and gamma oscillations recorded in the MDT, PCX, or OFC during four different periods: baseline (white), presampling (light gray), sampling (black), and pregoal port onset (dark gray). $\chi^{2}$ tests were used to compare the proportion of units between baseline and the other periods $\left({ }^{*} p<0.05 ;{ }^{* *} p<0.01\right)$. $D$, Representation of the mean population vector of all MDT units' activity relative to theta (left) and beta (right) oscillations recorded in the OFC (violet) and the PCX (pink). The length of the arrow represents the mean resultant vector length and the direction represents the mean phase angle (in degrees, see Materials and Methods) of MDT units during baseline, presampling, sampling, and pregoal port onset periods (from lighter to darker color, respectively). $E$, Summary of the dynamic changes of the olfactory trans-thalamic pathway during the olfactory task window. Only the changes occurring between MDT units and oscillations recorded in PCX and OFC relative to baseline and presampling period (plain circles) are represented. 
The results suggest significant behavior-dependent network dynamics, with enhanced MDT-PCX functional connectivity (i.e., increased phase locking between MDT spikes and LFP oscillations in the PCX) during odor sampling behavior and enhanced MDT-OFC functional connectivity during goal approach behavior compared with baseline and presampling periods.

Four rats exhibited reliable LFP signals in all three areas and MDT single units. Units and LFPs recorded in those four rats were analyzed ( $n=67$ task-modulated units). We measured the spike/LFP phase locking during different periods: presampling $(0.5 \mathrm{~s}$ ), sampling (we chose to reduce the sampling period to $0.5 \mathrm{~s}$ after nose poke onset to be able to compare to baseline, presampling and pregoal port onset periods), pregoal port onset $(0.5 \mathrm{~s})$, and baseline $(0.5 \mathrm{~s})$. Spike-LFP phase locking was measured between MDT spikes and LFPs recorded in MDT, PCX, and OFC (Rayleigh test). We examined three different oscillatory bands: theta $(1.5-12 \mathrm{~Hz})$, beta $(15-35 \mathrm{~Hz})$, and gamma $(40-90 \mathrm{~Hz})$. An example of MDT spike/PCX-theta phase locking during the different periods of interest is presented in Figure $5 B$. Below are described the changes in the proportion of MDT units significantly locked to LFPs oscillations during the different periods of the task for each structure and frequency band compared with baseline.

Overall, we observed that the major changes in spike/LFP phase locking relative to baseline (no task engagement) occurred in the theta band. In fact, as a population, the proportion of MDT single units phase locked to MDT theta was elevated in all three different epochs compared with baseline (proportion of units with significant phase locking: baseline vs presampling $\chi^{2}(1)=$ 4.87, $p<0.05$; baseline vs sampling $\chi^{2}(1)=7.74, p<0.01$; baseline vs pregoal port $\chi^{2}(1)=3.96, p<0.05$; Figure $5 C$ ). For MDT unit phase locking to PCX theta oscillations, there was no difference between baseline and presampling (baseline vs presampling $\left.\chi^{2}(1)=2.47, p=0.12\right)$; however, the proportion of MDT units significantly phase locked to PCX theta increased significantly during the sampling and pregoal port onset periods compared with baseline (baseline vs sampling $\chi^{2}(1)=10.77, p<$ 0.01 ; baseline vs pregoal port $\left.\chi^{2}(1)=5.195, p<0.05\right)$. Importantly, the percentage of single units phase locked to PCX theta during the sampling period was not only significantly higher than baseline but was also higher than during the presampling period (presampling vs sampling $\chi^{2}(1)=4.305, p<0.05$ ). Interestingly of the odorant selective units that were analyzed for the phase locking $(n=8), 25 \%$ presented a significant phase locking to PCX theta oscillations during the sampling period. Finally, for MDT unit phase locking to OFC theta oscillations, the only difference from baseline was during the sampling period (baseline vs sampling $\left.\chi^{2}(1)=4.74, p<0.05\right)$.

The changes in the proportion of MDT units significantly phase locked to theta oscillations were not related to changes in power of the LFPs oscillations as there was no significant effect of the period on the power in the theta band $\left(\mathrm{MDT}: F_{(3,3)}=3.245\right.$, $p=0.074$; PCX: $F_{(3,3)}=0.849, p=0.501$; OFC: $F_{(3,3)}=2.886$, $p=0.095)$.

For beta oscillations, there was a significant increase in the proportion of MDT units phase locked to beta oscillations recorded in the MDT during sampling compared with baseline (baseline vs sampling $\chi^{2}(1)=5.06, p<0.05$; Fig. $5 C$ ). There was also a significant increase of the percentage of MDT units phase locked to beta oscillations recorded in the OFC during the pregoal port onset period (baseline vs pregoal port, $\chi^{2}(1)=4.085$, $p<0.05)$ and importantly, this percentage was also significantly higher than during the presampling period (presampling vs pre- goal port, $\left.\chi^{2}(1)=5.25, p<0.05\right)$. Interestingly, the MDT units phase locked to PCX theta oscillation during sampling were in majority a different population of units than the ones phase locked to OFC beta oscillation during the pregoal port period although we observed rare cases in which at the single-unit level, the unit was able to shift coupling from PCX theta to OFC beta across sampling and pregoal port periods. Regarding the power of the LFPs in the beta band, there was no significant difference in the PCX or OFC between the different trial periods (PCX: $F_{(3,3)}=$ $1.159, p=0.378$; OFC: $\left.F_{(3,3)}=2.085, p=0.17\right)$. However there was a significant effect of the period on the power in the beta band in the $\operatorname{MDT}\left(F_{(3,3)}=4.554, p=0.033\right)$ but those changes did not correspond to the significant increase of the proportion of MDT units phase locked to beta oscillations in the MDT as the power of the LFPs beta oscillations was significantly higher during presampling and pregoal port periods compared with baseline, and higher during pregoal port period compared with sampling period (Fisher's post hoc test, $p<0.05$ ).

For gamma oscillations, the only effect was an increase of the percentage of MDT units phase locked to gamma oscillations recorded in the MDT during the presampling (baseline vs presampling $\chi^{2}(1)=4.83, p<0.05$; Fig. $\left.5 C\right)$. The power in the gamma band in the MDT significantly changed across periods $\left(F_{(3,3)}=\right.$ $7.074, p=0.0097)$ with a significant increase in power during the presampling period compared with baseline and sampling (Fisher's post hoc test, $p<0.05$ ). This increase could contribute to the significant increase of the proportion of MDT units phase locked to MDT gamma oscillations.

During both the sampling and the pregoal port onset periods, MDT units phase locked their activity to PCX and/or OFC (Fig. $5 C-E)$. In addition to looking at the percentage of MDT units significantly locked to PCX and OFC oscillations, we also analyzed the mean population vector of all MDT units relative to those oscillations. Interestingly, we observed that the mean vector phase of all MDT units' activity relative to the negative trough of PCX theta cycle was clustered between $-8.5^{\circ}$ (i.e., $351.5^{\circ}$ ) and $25.3^{\circ}$ during the four periods of interest while it was between $249.8^{\circ}$ and $297.3^{\circ}$ relative to the negative trough of OFC theta cycle (Fig. 5D). Therefore, while MDT units were phase locked to theta oscillations in both PCX and OFC, the MDT population presented different mean phases relative to the trough of theta cycle in these two structures. We cannot determine whether locking to PCX theta preceded that of OFC theta from these data. However, this phase lag relative to the trough of theta cycle was present during each period and ranged between 79 and $136^{\circ}$. It should also be noted that the strength (population vector length) of MDT population phase locking to theta oscillation in PCX was, for example, less than to the OFC during the sampling period, suggesting that individual MDT units did not necessarily present the same preference of PCX's theta phase during sampling. Finally, the mean vector phases relative to the trough of beta oscillations in PCX and OFC during the four different periods were distributed throughout the cycle with no apparent cluster as a function of the structure or the period (Fig. 5D)

Phase locking of MDT unit activity with different network components was period-specific and can be summarized as follows (Fig. 5E): during the presampling period, the proportion of MDT units phase locked to LFP's was enhanced in the MDT, but not in the PCX and OFC, compared with baseline. During the sampling period, MDT units phase locked, not only to MDT beta and theta oscillations, but the proportion of MDT units phase locked to PCX and OFC also started to increase significantly rel- 
A1
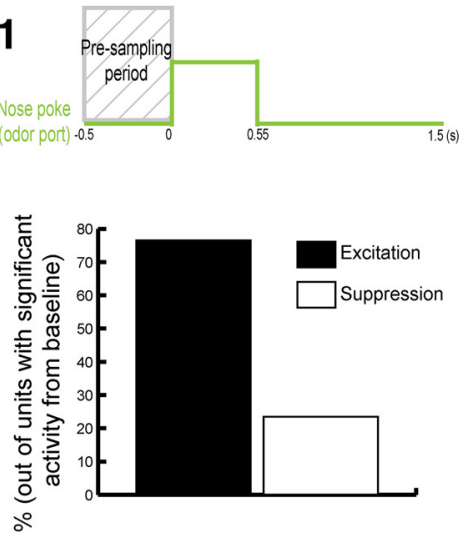

A2
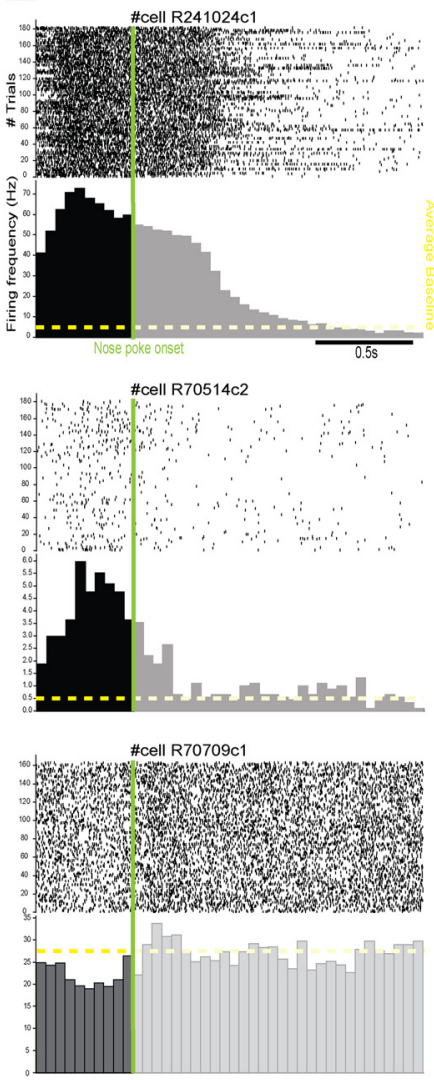

A3

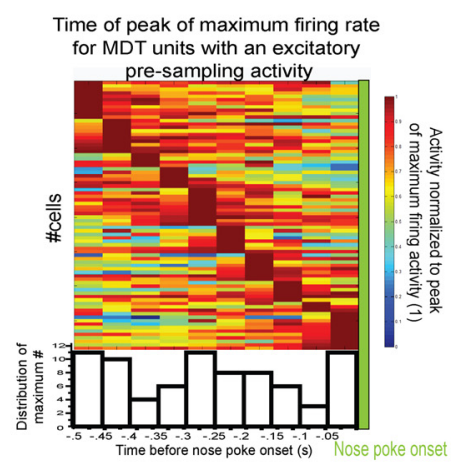

B

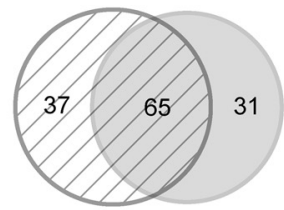

102 Units with significant

102 pre-sampling activity

96 Units with significant

C1
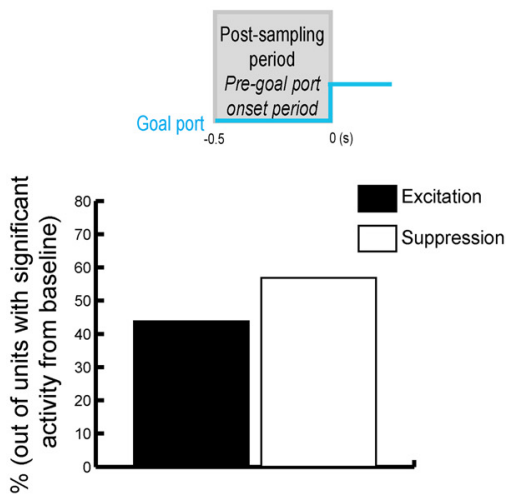

C2

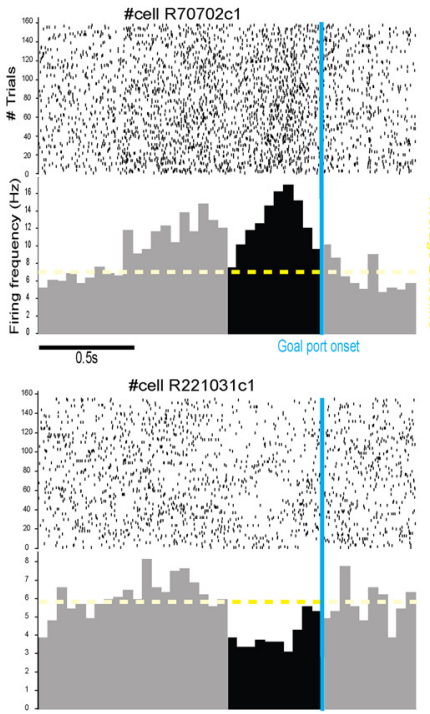

C3

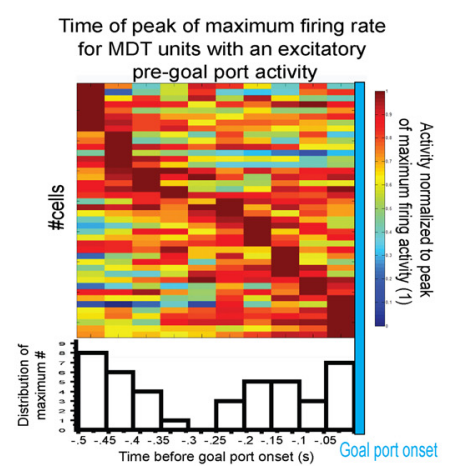

ative to baseline: MDT units were phase locked to theta oscillations recorded in PCX and OFC, with different mean phase lags in the two structures. This enhancement during the sampling period was most robust in the PCX because the MDT unit phase locking to PCX theta was also significantly higher than during the presampling period, whereas phase locking to OFC did not differ significantly from presampling. During the pregoal port onset period, the network changed again: MDT units were now significantly phase locked to OFC beta oscillations relative to baseline and presampling periods in addition to the theta coupling with PCX and MDT.

\section{Complex activity in the MDT beyond the sampling period: trial initiation and spatial information}

Considering the fact that the MDT is a higher-order thalamic nucleus (Guillery, 1995) and taking advantage of the design of the task, we also wanted to characterize MDT single-unit activity during the initiation of the trial (presampling period) and test whether the MDT, similar to its cortical target the OFC, is involved in representing spatial information.

Temporal pattern of MDT activity during presampling and pregoal port periods To characterize the temporal patterns of MDT single-unit activity during the initi-

$\leftarrow$

activity deemed excitatory (black) or suppressive (white). $\mathbf{A}$, Examples of raster plots and PSTHs of three units displaying a significant difference between presampling activity and baseline (Wilcoxon rank-sum test, $p<0.05$ ). Raster plots and PSTHs are triggered by the nose poke onset (green). A3, Top, Color scale representation of the time of the peak of maximum firing rate for MDT units with a significant excitatory presampling activity (compared with baseline). The activity was normalized to the maximum firing rate during the presampling period. Dark red represents 1 , the maximum firing rate of activity. Bottom, Histogram distribution of the time of the maximum firing rate during presampling (note that, for five units, there were two equal maximum values; to simplify the representation, we used the first maximum). $\boldsymbol{B}$, Diagram representing MDT units that present a significant difference of activity between baseline and presampling and/or pregoal port period (Wilcoxon rank-sum test, $p<0.05)$. C, Temporal pattern of activity during the pregoal port period $(0.5 \mathrm{~s}$ preceding goal port onset). (1, Histogram of the percentage of units (of the units with a significant difference of activity from baseline $n=$ 96/155) with an activity deemed excitatory (black) or suppressive (white). C2, Examples of raster plots and PSTHs of two units displaying a significant difference between pregoal port activity and baseline (Wilcoxon rank-sum test, $p<0.05$ ). Raster plots and PSTHs are triggered by the goal port onset (blue). C3, Same as $A 3$ except that the period of activity considered

Figure 6. Complex temporal patterns of MDT unit activity during presampling $(\boldsymbol{A})$ and pregoal port onset $(\boldsymbol{C})$ periods. $\boldsymbol{A}$, Temporal pattern of activity during the presampling period ( 0.5 s preceding nose poke onset) compared with baseline (Fig. 1D). $\boldsymbol{A}$, Histogram of the percentage of units (of the units with a significant difference of activity from baseline $n=102 / 155$ ) with an here is the pregoal port period (note that, for two units, there were equal maximum values, so, as in $\mathbf{A}$, we used the first maximum). 
A

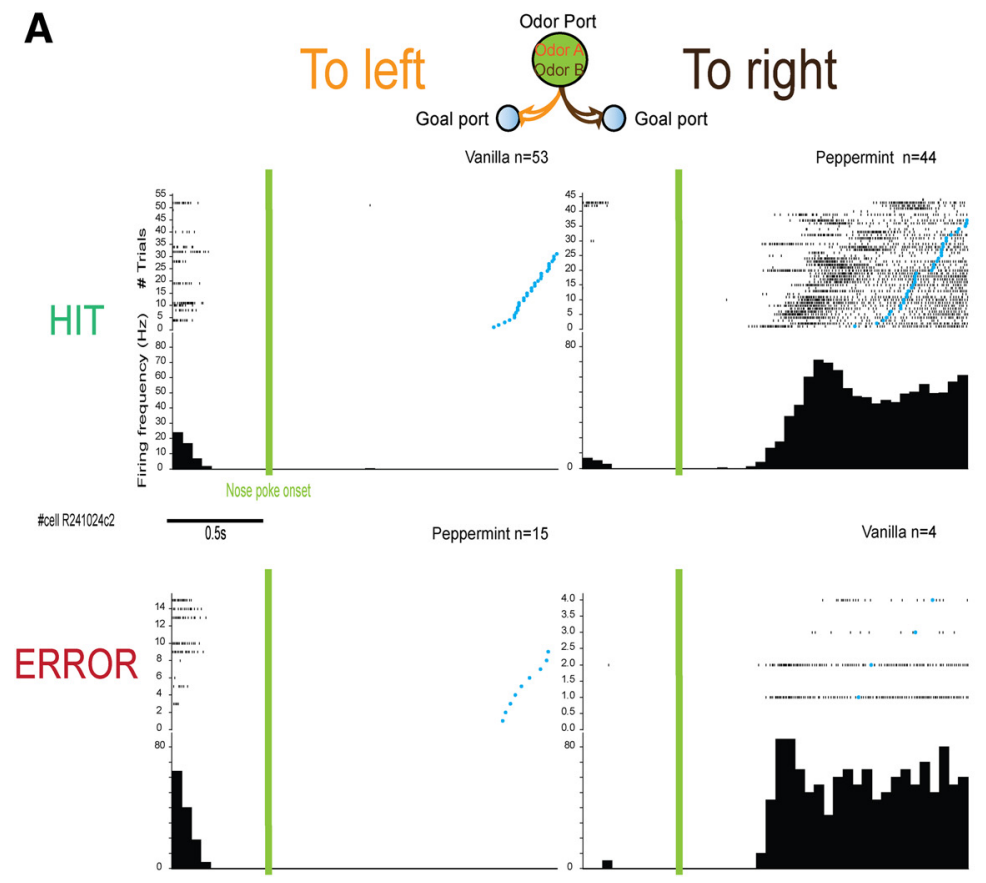

B
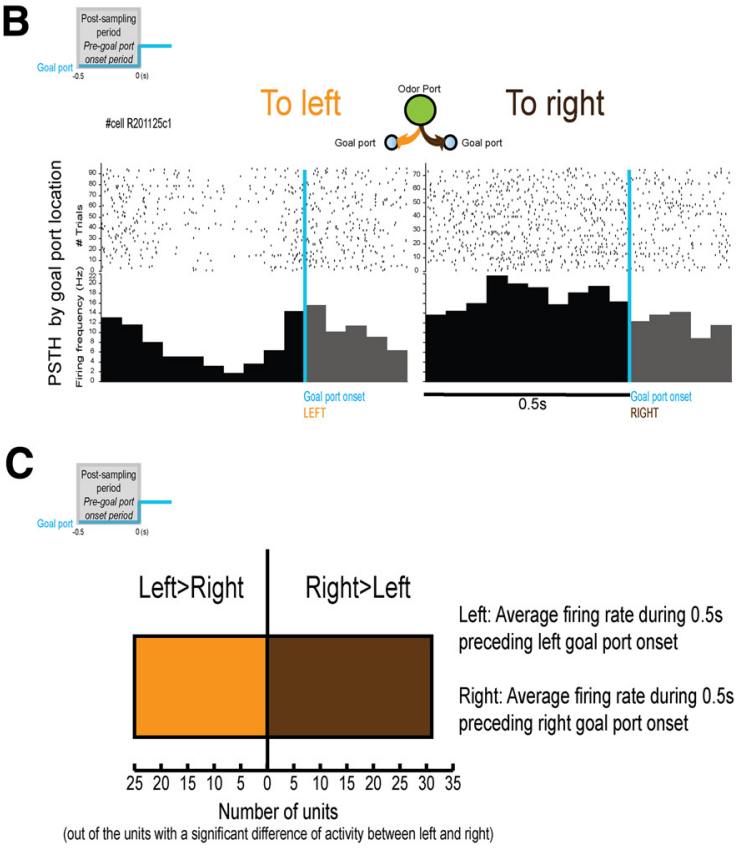

Figure 7. Encoding of goal port location. $A$, Example of a unit's raster plots and PSTHs as a function of hits (top) and errors (bottom) and the odors used (performance: $84 \%$ ). Raster plots and PSTHs are triggered by the nose poke onset (green). Blue dots represent the goal port onsets (only trials with the goal port entry within $2 \mathrm{~s}$ after the nose poke onset are displayed). $\boldsymbol{B}$, Example of a unit's raster plots and PSTHs by goal port location. Raster plots and PSTHs are triggered by the goal port onset (blue). This unit presents a significant difference of pregoal port activity between moving to the right or the left goal port (Wilcoxon signed-rank test, $p<0.05)$. C, Of the units $(n=56 / 155)$ with a significant difference of pregoal port activity between left and right goal ports, $55 \%$ display an average firing rate superior during the right versus the left pregoal port period.

ation of the trial, we compared the presampling activity with baseline (no task engagement). Furthermore, to decipher whether this presampling activity was specific to trial initiation, we also compared the pregoal port activity (a period when the rat is also initiating a movement toward a port) to baseline. We observed that some cells displayed a difference of activity during the presampling period and not during the pregoal port period, some during both periods, and some only during pregoal port period, suggesting that specific cells may be selective to the trial initiation and may be anticipatory related, whereas others may display modified activity that could be spatial, movement, or task related (Fig. 6).

Relative to the presampling period, we observed that $66 \%$ of MDT units display a significant difference of activity between the presampling period and baseline (102/155; Wilcoxon rank-sum test). Of those units, a majority ( $76.5 \%)$ displayed an excitatory pattern compared with baseline (Fig. 6A1,A2). Interestingly, temporal patterns of excitatory activity during the presampling period were diverse, with some units displaying increased firing rate $0.5 \mathrm{~s}$ before the nose poke onset and others at $0.25 \mathrm{~s}$ or right before the nose poke onset (Fig. 6A2,A3).

Importantly, a subset of those MDT units (36\%) only displayed a difference of activity during the presampling period (Fig. $6 A 2$, middle and bottom) and not during pregoal port period. This suggests that these cells are not simply displaying spatial- or movement-related activity. In contrast to these selective presampling cells, other cells also displayed changes in activity during the pregoal port period (65 of 102 units displaying a significant activity during presampling period; Fig. $6 B$ ). This latter group may be displaying spatial- or movement-related activity. For example, during both the presampling and the pregoal port periods, there is a movement toward a port and the rats are moving in space to either initiate a trial or to respond by moving to one of the goal ports. Is MDT single-unit activity for these cells similar when the rat is approaching the central port and the goal port? When looking specifically at the MDT units displaying a significant activity during both presampling and pregoal port periods, we observed that, although some MDT units present the same pattern of activity in both periods (excitatory vs suppressive), others do not (26/65). Therefore, even though MDT units can present a significant difference of activity during presampling and pregoal port, their activity is not necessarily similar during both periods. In fact, when looking at the general population of units displaying a significant difference of activity between baseline and the pregoal port period ( $n=96 / 155$, Wilcoxon rank-sum test; Fig. $6 B)$, we observed that, in contrast to the presampling period displaying a majority of excitatory activity, the excitatory pattern was not dominant during the pregoal port period (44\% of excitation; Fig. $6 C 1, C 2)$ and a majority of units displayed a maximal firing rate 0.5-0.4 $\mathrm{s}$ and also right before the goal port onset (Fig. 6C3).

Therefore, MDT units can present a variety of task-related activity patterns, some specific to the presampling period, others to the pregoal port period, and others displaying modified activity during both periods compared with baseline (Fig. 6B). This suggests that MDT units can encode various sensorimotor aspects of the task. In the last section, we will discuss one of those aspects: the spatial representation in the MDT.

\section{Encoding of goal location and choice direction}

The OFC, with which the MDT has dense reciprocal connections, has been demonstrated to encode choice direction and goal location during a two-alternative odor discrimination task (Feierstein et al., 2006). Is this representation of spatial goal also present in the MDT?

As illustrated in Figure $7 A$, this unit displays a robust increase of firing rate when the rat is moving to the right goal port and this 

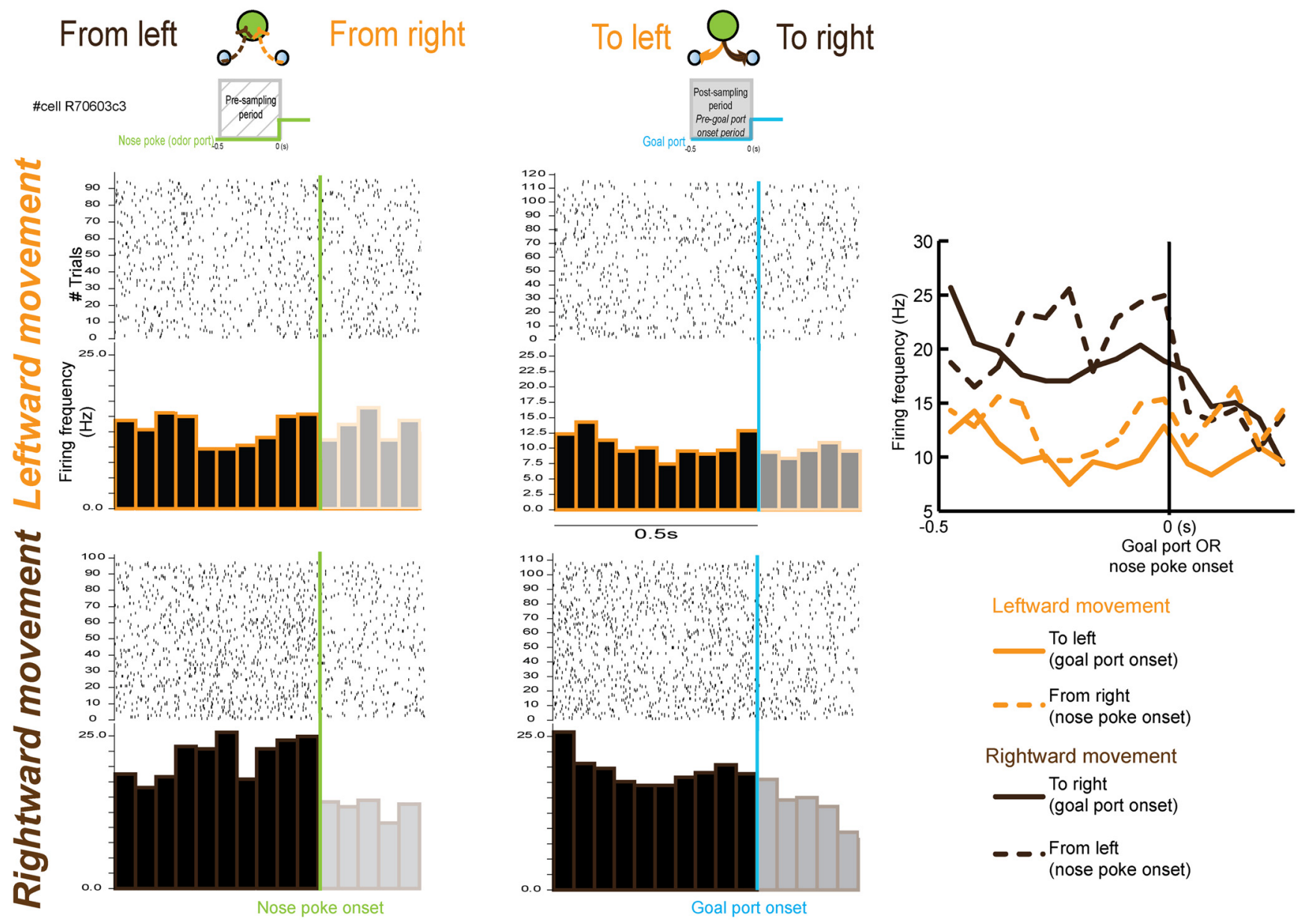

Figure 8. Encoding of choice direction. Left and middle, Example of raster plots and PSTHs from one unit as a function of the direction of the movement. Raster plots and PSTHs are aligned to either the nose poke onset (green, left) or the goal port onset (blue, right). Trials are grouped according to direction of the movement: leftward movement in orange and rightward movement in brown. Periods of interest are the $0.5 \mathrm{~s}$ either preceding the nose poke onset (left) or the goal port onset (right). Right, Combined representation of the firing rate of the unit presented in the left panels as a function of the direction of the movement. This cell fired selectively for the rightward movement in both periods of the task.

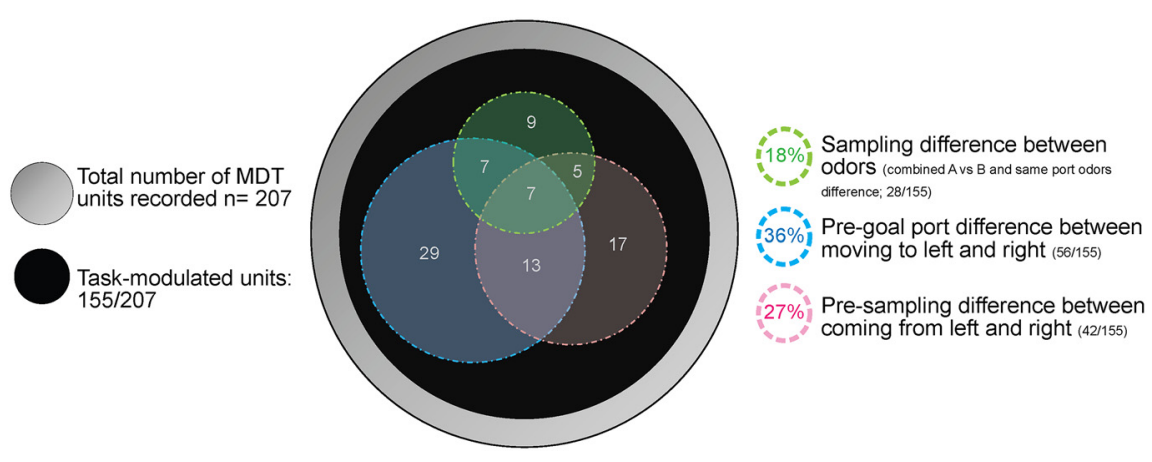

Figure 9. Schematic representation of the stimulus-dependent activity of MDT units. The large gray circle represents the total number of MDT units recorded $(n=207)$. The black circle represents the task-modulated units $(n=155)$. The green circle represents the units displaying a difference of sampling activity between the odors (for simplicity, we combined the cells that present a difference between the odors in the simple two odor discrimination task, $n=15$, and the ones that present a difference of activity between the five odors associated with the same side, $n=13$ ). In the blue circle are represented the units displaying a difference of pregoal port activity between moving to the left and right goal port $(n=56)$. In the red circle are represented the units displaying a difference of presampling activity between coming from the left and right goal port $(n=42)$. Some units only display difference of activity in one of the circles, whereas others present differences during multiple periods of the task and are represented in the overlapping part of the circles.

increase was present for both hit and error trials. Regarding hit and error trials, we compared the postsampling period between hit and error trials (0.55-1.5 s after nose poke onset; the analysis refers to the activity of units with sufficient error trials, see Ma- terials and Methods) and observed that $16 \%$ of MDT units displayed a significant change in postsampling activity between hit and errors trials (10/61; Wilcoxon signed-rank test). However, when examining the raw PSTHs, we observed that the main effect was not the difference between hit and error trials, but rather the goal location (Fig. 7A). To quantify this goal port location selectivity, we compared the pregoal port onset activity between the left and right goal port locations on all the task-modulated units (Fig. $7 B$, hit and errors combined). We observed that $36 \%$ of MDT units (56/155) display a significant difference of pregoal port activity between moving to the right or to the left goal port from the sampling port. Importantly, this percentage was not different between high performance and low performance sessions (performance $<80 \%$ vs $>=80 \%$, $\left.\chi^{2}(1)=0.031, p=0.86\right)$. Moreover, although recordings were only performed in the left hemisphere, the MDT units did not have a preference for rightward or leftward movement, with 55\% of MDT units displaying an average 
firing rate superior for the right versus the left pregoal port onset period (Fig. 7C).

At least two possible interpretations can be drawn from the fact that MDT units display leftward and rightward movementrelated activity: it may represent either a coding of goal port location and/or direction/orientation of movement. The most likely interpretation is that the MDT codes for both. In fact, we observed that of the 56 units displaying a difference of pregoal activity between moving toward the right or left goal ports, $36 \%$ (20/56) also display a difference when moving toward the odor port (with a selection of trials when the movements were occurring in the $2 \mathrm{~s}$ preceding the nose poke onset; Figs. 8, 9). A majority of the neurons displaying a difference between sides during both the presampling and the pregoal port onset period had the same direction movement preference (leftward vs rightward movement), so those neurons represent the direction/orientation of the movement (13/20; Fig. 8). The other cells displaying a difference between sides during both the presampling and the pregoal port onset period but with different preference to the movement may code the spatial location within the operant box (left vs right), although the $n$ for this specific category was small $(n=7)$.

\section{Discussion}

Although the role of the MDT in cognition is increasingly well established (Mitchell and Chakraborty, 2013), a singular function of the MDT has been woefully unexplored: its olfactory function. Our aim here was to characterize the activity of the MDT and the relationships among the olfactory cortico-thalamocortical pathway in rats performing a two-alternative odor discrimination task. We demonstrated that a subset of MDT units can display odorant selectivity and that the PCX-MDT-OFC network changes dynamically over the course of the two-alternative discrimination task. In addition to this sensory function, the MDT also presents specific modulations of presampling activity and seems to encode spatio-motor variables. Together, the results suggest a rich representation of olfactory and other information within MDT required to perform this odor-guided task.

\section{Odorant representation in the MDT}

The MDT receives direct input from various olfactory areas, including the PCX and the OFC (Tham et al., 2009; Courtiol and Wilson, 2015). We observed that $15 \%$ of MDT units display a significant difference of sampling activity between the two odorants presented in the task. Although MDT units can display odorant selectivity even in anesthetized animals (Imamura et al., 1984; Courtiol and Wilson, 2014), in the awake animals used here, behavioral variables such as goal port location or choice direction could influence this activity. Switching the sides of rewarded ports, modifying the geometry of the operant box, or associating multiple odors to a same reward port could clearly distinguish whether the MDT units were selective to odorant stimuli. In fact, we associated five odors with the same reward port and observed, not only that $25 \%$ of MDT units tested in this design displayed a significant difference of activity between those odors (Fig. 4), but also that, at the neuronal population level, there was a significant decorrelation of activity during the sampling period between the odorants, helping to confirm MDT single-unit odorant selectivity in awake rats. Moreover, the percentage of odorant-selective units in the MDT observed is consistent with data described by Kawagoe et al. (2007) recording MDT units in rats performing a task in which odorant cues were associated or not to a reward. Interestingly, this percentage also matches that observed in rat
OFC in a task similar to the one used here (Feierstein et al., 2006). This similarity of odorant selectivity in both structures and their well described reciprocal connections raises the questions of which structure is driving which and what is the MDT adding to olfactory processing?

Lesions of the MDT do not alter simple odor discrimination, but do impair performance in a difficult odor discrimination task (Eichenbaum et al., 1980; Staubli et al., 1987). In this context, we can hypothesize that the odor selectivity observed here may not be used to discriminate odors per se, as is perhaps the case in the olfactory bulb or PCX (Kay and Laurent, 1999; Cury and Uchida, 2010; Chapuis and Wilson, 2012; Gire et al., 2013), but rather information from olfactory areas may be used to inform the MDT to flexibly guide behavior according to the odorant presented. The MDT may then work in concert with the OFC to integrate stimulus-outcome association to achieve the behavior (Roesch et al., 2007; Farovik et al., 2015). This hypothesis is in part supported by the analysis of the functional connectivity within the olfactory transthalamic pathway. In fact, during the presampling period, there is no significant change in the proportion of MDT units phase locked to the PCX and OFC oscillations compared with baseline. However, during the sampling period and compared with baseline, there is a significant increase of the proportion of MDT units phase locked to both the PCX and the OFC and, specifically, MDT single-unit phase locking to PCX theta is not only significantly higher than baseline, but also higher than presampling (Fig. 5). This may signify that, during the sampling period, there is a specific engagement of the PCX sending sensory information to the MDT. This observation, consistent with recent findings in the monkey visual system showing that theta and gamma oscillations support feedforward information flow (Bastos et al., 2015), is currently being tested by specifically suppressing the PCX input to the MDT during the sampling period.

During the pregoal port period, the network dynamic changes again: MDT units are significantly phase locked to OFC beta oscillations relative to baseline and presampling periods in addition to the theta coupling with PCX and MDT. Beta oscillations are associated with interarea communication (Tallon-Baudry et al., 2001) and have been hypothesized to reflect the maintenance of the current sensorimotor set (Engel and Fries, 2010). Interestingly, regional connectivity between MDT and medial prefrontal cortex in the beta band has been shown to increase during the choice phase of a delay nonmatch to sample task and was proposed to represent the maintenance of the information acquired during the sample phase (Parnaudeau et al., 2013). By analogy, the synchronization of MDT spikes to OFC beta oscillations may reflect the maintenance of the olfactory information acquired during the sampling phase that is necessary to guide behavior appropriately.

\section{Presampling activity in the MDT: anticipation?}

A majority of studies using the two-alternative task have used the presampling period as a baseline. In our specific case, we used a separate period that allowed us to have a baseline that could be used for all three epochs of the task, was independent of specific task-related behaviors such as anticipation or response to recent reward, and was determined to be necessary given the robust presampling MDT activity (Figs. 2, 6). The baseline period used here was taken during the recording session when the rat was quiet and awake but not actively engaged in the task. Using this baseline, we observed that a substantial population of MDT units 
presented significant activity modulation during the presampling period (Fig. 6). Of those units, a subset was specific to this presampling period. In a dynamic delayed nonmatching-to-position task, some MDT units responded in anticipation of reinforcement (Mair et al., 2015). The presampling activity of the MDT units observed in the present results may also be anticipatory related. Moreover, during the presampling period and compared with baseline, there is a significant increase of the proportion of MDT units locked to MDT-gamma oscillations (Fig. 5C, associated with an increase of gamma-oscillation power), which have been associated with attention-related processes (Fries et al., 2001). In addition, MDT population activity across trials was most highly correlated as the animal initiated a trial immediately before odor onset, suggesting the emergence of a stable pretrial MDT "state" just as the animal prepared to sample the odor. Interestingly, several studies suggest a contribution of the MDT in olfactory attention and error prediction in humans (Plailly et al., 2008; Tham et al., 2009, 2011; Veldhuizen and Small, 2011; Zelano et al., 2011; Olofsson et al., 2013).

These results, as well as the known neuromodulatory inputs to the MDT (Hallanger et al., 1987; Groenewegen, 1988; Varela, 2014), suggest an anticipatory-related activity during the presampling period. To confirm this, future work will involve recording MDT activity during the initial phase of training. In fact, if the presampling activity that we observed is anticipatory, then it should develop over the course of task acquisition.

\section{Spatio-motor representation in the MDT}

Approximately half of MDT neurons (78/155; Fig. 9, blue and red circles) showed differential activity as a function of the movement: either moving to the right or left goal port or/and when moving toward the central port either from the right or left goal port. Furthermore, the differential firing of some neurons was specific to the pregoal port period (Figs. 7, 9). This activity is consistent with a representation of the goal port location, but may also reflect selectivity for the preceding odor stimulus associated with the port. Based on our results, we do not believe that to be the case. In fact, if we consider MDT units displaying a differential activity between moving to the right or left goal port, only a small portion also displays a difference between the odorants (Fig. 9). Moreover, Han et al. (2013) demonstrated that the MDT can convey signals about the goal location during the reward period in a delayed spatial alternation task.

Some units were not selective to the goal port location, but rather shared a direction preference during both the movement toward the central port and that toward the goal port (Fig. 8). The units presenting the same preference of movement suggest that the MDT is not only representing spatial information, but also movement information. This observation again matches closely the results obtained in the OFC in a similar task (Feierstein et al., 2006). Further work is required to better define the role of the MDT-OFC pathway in olfaction and one challenge will be to understand how the MDT affects OFC activity and vice versa.

\section{Conclusions}

Our results reveal the complex patchwork of MDT unit activity during a two-alternative odor discrimination task in freely moving rats. Based on these results, as well as previous work (Murakami et al., 2005; Kay and Sherman, 2007), the MDT may not be considered as a primary sensory thalamic relay performing sensory coding, gain control, or state-dependent modulation. It is more likely a higher-order thalamus integrating olfactory information for odor-guided behavior. In fact, encoding various information categories and being a structure receiving convergent inputs from motor, cognitive, and emotional areas and sending inputs to distributed cortical areas places the MDT as a critical node to drive and synchronize the activity among those areas to attain complex odor-related goal-directed behavior (Saalmann, 2014; Mair et al., 2015).

\section{References}

Bastos AM, Vezoli J, Bosman CA, Schoffelen JM, Oostenveld R, Dowdall JR, De Weerd P, Kennedy H, Fries P (2015) Visual areas exert feedforward and feedback influences through distinct frequency channels. Neuron 85:390-401. CrossRef Medline

Bay HH, Cavdar S (2013) Regional connections of the mediodorsal thalamic nucleus in the rat. J Integr Neurosci 12:201-219. CrossRef Medline

Chapuis J, Wilson DA (2012) Bidirectional plasticity of cortical pattern recognition and behavioral sensory acuity. Nat Neurosci 15:155-161. CrossRef Medline

Cohen Y, Putrino D, Wilson DA (2015) Dynamic cortical lateralization during olfactory discrimination learning. J Physiol 593:1701-1714. CrossRef Medline

Courtiol E, Wilson DA (2014) Thalamic olfaction: characterizing odor processing in the mediodorsal thalamus of the rat. J Neurophysiol 111:1274-1285. CrossRef Medline

Courtiol E, Wilson DA (2015) The olfactory thalamus: unanswered questions about the role of the mediodorsal thalamic nucleus in olfaction. Front Neural Circuits 9:49. CrossRef Medline

Cury KM, Uchida N (2010) Robust odor coding via inhalation-coupled transient activity in the mammalian olfactory bulb. Neuron 68:570-585. CrossRef Medline

Eichenbaum H, Shedlack KJ, Eckmann KW (1980) Thalamocortical mechanisms in odor-guided behavior. I. Effects of lesions of the mediodorsal thalamic nucleus and frontal cortex on olfactory discrimination in the rat. Brain Behav Evol 17:255-275. CrossRef Medline

Engel AK, Fries P (2010) Beta-band oscillations: signalling the status quo? Curr Opin Neurobiol 20:156-165. CrossRef Medline

Farovik A, Place RJ, McKenzie S, Porter B, Munro CE, Eichenbaum H (2015) Orbitofrontal cortex encodes memories within value-based schemas and represents contexts that guide memory retrieval. J Neurosci 35 : 8333-8344. CrossRef Medline

Feierstein CE, Quirk MC, Uchida N, Sosulski DL, Mainen ZF (2006) Representation of spatial goals in rat orbitofrontal cortex. Neuron 51: 495-507. CrossRef Medline

Ferrer NG (1969) Efferent projections of the anterior olfactory nucleus. J Comp Neurol 137:309-320. CrossRef Medline

Fries P, Reynolds JH, Rorie AE, Desimone R (2001) Modulation of oscillatory neuronal synchronization by selective visual attention. Science 291: 1560-1563. CrossRef Medline

Gire DH, Whitesell JD, Doucette W, Restrepo D (2013) Information for decision-making and stimulus identification is multiplexed in sensory cortex. Nat Neurosci 16:991-993. CrossRef Medline

Groenewegen HJ (1988) Organization of the afferent connections of the mediodorsal thalamic nucleus in the rat, related to the mediodorsalprefrontal topography. Neuroscience 24:379-431. CrossRef Medline

Guillery RW (1995) Anatomical evidence concerning the role of the thalamus in corticocortical communication: a brief review. J Anat 187: 583-592. Medline

Hallanger AE, Levey AI, Lee HJ, Rye DB, Wainer BH (1987) The origins of cholinergic and other subcortical afferents to the thalamus in the rat. J Comp Neurol 262:105-124. CrossRef Medline

Han J, Lee JH, Kim MJ, Jung MW (2013) Neural activity in mediodorsal nucleus of thalamus in rats performing a working memory task. Front Neural Circuits 7:128. CrossRef Medline

Illig KR (2005) Projections from orbitofrontal cortex to anterior piriform cortex in the rat suggest a role in olfactory information processing. J Comp Neurol 488:224-231. CrossRef Medline

Imamura K, Onoda N, Takagi SF (1984) Odor response characteristics of thalamic mediodorsal nucleus neurons in the rabbit. Jpn J Physiol 34: 55-73. CrossRef Medline

Inagaki S, Kubota Y, Shinoda K, Kawai Y, Tohyama M (1983) Neurotensincontaining pathway from the endopiriform nucleus and the adjacent prepiriform cortex to the dorsomedial thalamic nucleus in the rat. Brain Res 260:143-146. CrossRef Medline 
Jackson JC, Benjamin RM (1974) Unit discharges in the mediodorsal nucleus of the rabbit evoked by electrical stimulation of the olfactory bulb. Brain Res 75:193-201. CrossRef Medline

Kawagoe T, Tamura R, Uwano T, Asahi T, Nishijo H, Eifuku S, Ono T (2007) Neural correlates of stimulus-reward association in the rat mediodorsal thalamus. Neuroreport 18:683-688. CrossRef Medline

Kay LM, Laurent G (1999) Odor- and context-dependent modulation of mitral cell activity in behaving rats. Nat Neurosci 2:1003-1009. CrossRef Medline

Kay LM, Sherman SM (2007) An argument for an olfactory thalamus. Trends Neurosci 30:47-53. CrossRef Medline

Krettek JE, Price JL (1977) The cortical projections of the mediodorsal nucleus and adjacent thalamic nuclei in the rat. J Comp Neurol 171:157-191. CrossRef Medline

Kuroda M, Price JL (1991) Synaptic organization of projections from basal forebrain structures to the mediodorsal thalamic nucleus of the rat. J Comp Neurol 303:513-533. CrossRef Medline

Kuroda M, Murakami K, Kishi K, Price JL (1992) Distribution of the piriform cortical terminals to cells in the central segment of the mediodorsal thalamic nucleus of the rat. Brain Res 595:159-163. CrossRef Medline

Mair RG, Miller RL, Wormwood BA, Francoeur MJ, Onos KD, Gibson BM (2015) The neurobiology of thalamic amnesia: Contributions of medial thalamus and prefrontal cortex to delayed conditional discrimination. Neurosci Biobehav Rev 54:161-174. CrossRef Medline

Mitchell AS, Chakraborty S (2013) What does the mediodorsal thalamus do? Front Syst Neurosci 7:37. CrossRef Medline

Murakami M, Kashiwadani H, Kirino Y, Mori K (2005) State-dependent sensory gating in olfactory cortex. Neuron 46:285-296. CrossRef Medline

Olofsson JK, Rogalski E, Harrison T, Mesulam MM, Gottfried JA (2013) A cortical pathway to olfactory naming: evidence from primary progressive aphasia. Brain 136:1245-1259. CrossRef Medline

Orona E, Gabriel M (1983) Multiple-unit activity of the prefrontal cortex and mediodorsal thalamic nucleus during acquisition of discriminative avoidance behavior in rabbits. Brain Res 263:295-312. CrossRef Medline

Ostlund SB, Balleine BW (2008) Differential involvement of the basolateral amygdala and mediodorsal thalamus in instrumental action selection. J Neurosci 28:4398-4405. CrossRef Medline

Oyoshi T, Nishijo H, Asakura T, Takamura Y, Ono T (1996) Emotional and behavioral correlates of mediodorsal thalamic neurons during associative learning in rats. J Neurosci 16:5812-5829. Medline

Parnaudeau S, O’Neill PK, Bolkan SS, Ward RD, Abbas AI, Roth BL, Balsam PD, Gordon JA, Kellendonk C (2013) Inhibition of mediodorsal thalamus disrupts thalamofrontal connectivity and cognition. Neuron 77: 1151-1162. CrossRef Medline

Plailly J, Howard JD, Gitelman DR, Gottfried JA (2008) Attention to odor modulates thalamocortical connectivity in the human brain. J Neurosci 28:5257-5267. CrossRef Medline

Powell TP, Cowan WM, Raisman G (1963) Olfactory relationships of the diencephalon. Nature 199:710-712. Medline
Price JL (1985) Beyond the primary olfactory cortex: olfactory-related areas in the neocortex, thalamus and hypothalamus. Chem Senses 10:239-258. CrossRef

Price JL, Slotnick BM (1983) Dual olfactory representation in the rat thalamus: an anatomical and electrophysiological study. J Comp Neurol 215: 63-77. CrossRef Medline

Rennaker RL, Ruyle AM, Street SE, Sloan AM (2005) An economical multichannel cortical electrode array for extended periods of recording during behavior. J Neurosci Methods 142:97-105. CrossRef Medline

Roesch MR, Stalnaker TA, Schoenbaum G (2007) Associative encoding in anterior piriform cortex versus orbitofrontal cortex during odor discrimination and reversal learning. Cereb Cortex 17:643-652. Medline

Saalmann YB (2014) Intralaminar and medial thalamic influence on cortical synchrony, information transmission and cognition. Front Syst Neurosci 8:83. CrossRef Medline

Schoenbaum G, Eichenbaum H (1995) Information coding in the rodent prefrontal cortex. I. Single-neuron activity in orbitofrontal cortex compared with that in pyriform cortex. J Neurophysiol 74:733-750. Medline

Slotnick BM, Kaneko N (1981) Role of mediodorsal thalamic nucleus in olfactory discrimination learning in rats. Science 214:91-92. CrossRef Medline

Staubli U, Schottler F, Nejat-Bina D (1987) Role of dorsomedial thalamic nucleus and piriform cortex in processing olfactory information. Behav Brain Res 25:117-129. CrossRef Medline

Tallon-Baudry C, Bertrand O, Fischer C (2001) Oscillatory synchrony between human extrastriate areas during visual short-term memory maintenance. J Neurosci 21:RC177. Medline

Tham WW, Stevenson RJ, Miller LA (2009) The functional role of the medio dorsal thalamic nucleus in olfaction. Brain Res Rev 62:109-126. CrossRef Medline

Tham WW, Stevenson RJ, Miller LA (2011) The impact of mediodorsal thalamic lesions on olfactory attention and flavor perception. Brain Cogn 77:71-79. CrossRef Medline

Varela C (2014) Thalamic neuromodulation and its implications for executive networks. Front Neural Circuits 8:69. CrossRef Medline

Veldhuizen MG, Small DM (2011) Modality-specific neural effects of selective attention to taste and odor. Chem Senses 36:747-760. CrossRef Medline

Yarita H, Iino M, Tanabe T, Kogure S, Takagi SF (1980) A transthalamic olfactory pathway to orbitofrontal cortex in the monkey. J Neurophysiol 43:69-85. Medline

Yu C, Fan D, Lopez A, Yin HH (2012) Dynamic changes in single unit activity and gamma oscillations in a thalamocortical circuit during rapid instrumental learning. PLoS One 7:e50578. CrossRef Medline

Zelano C, Mohanty A, Gottfried JA (2011) Olfactory predictive codes and stimulus templates in piriform cortex. Neuron 72:178-187. CrossRef Medline 